\title{
Mechanistic Insight into High Yield Electrochemical Nitrogen Reduction to Ammonia using Lithium Ions
}

\author{
Anku Guha, Sreekanth Narayanaru, Nisheal M. Kaley, D. Krishna Rao, Jagannath Mondal, and \\ Tharangattu N. Narayanan*
}
Tata Institute of Fundamental Research - Hyderabad, Sy. No. 36/P, Gopanapally Village, Serilingampally Mandal, Hyderabad - 500107, India.

(Corresponding author: tnn@tifrh.res.in or tn_narayanan@yahoo.com) 


\begin{abstract}
Development of methods for economically feasible greener ammonia $\left(\mathrm{NH}_{3}\right)$ production is gaining tremendous scientific attention. $\mathrm{NH}_{3}$ has its importance in fertilizer industry and it is envisaged as a safer liquid hydrogen carrier for futuristic energy resources. Here, an aqueous electrolysis based $\mathrm{NH}_{3}$ production in ambient conditions is reported, which yields high faradaic efficiency $(\sim 12 \%) \mathrm{NH}_{3}$ via nitrogen reduction reaction $(\mathrm{NRR})$ at lower over potentials $(\sim-0.6 \mathrm{~V}$ vs. $\mathrm{RHE}$ or $-1.1 \mathrm{~V}$ vs. $\mathrm{Ag} / \mathrm{AgCl})$. Polycrystalline copper $(\mathrm{Cu})$ and gold $(\mathrm{Au})$ are used as electrodes for electrochemical NRR, where the electrolyte which yields high amount of $\mathrm{NH}_{3}(\sim 41$ $\mu \mathrm{mol} / \mathrm{L}$ ) is $5 \mathrm{M} \mathrm{LiClO}_{4}$ in water with $\mathrm{Cu}$ as working electrode. A detailed study conducted here establishes the role of $\mathrm{Li}^{+}$in stabilizing nitrogen near to the working electrode - augmenting the NRR in comparison to its competitor - hydrogen evolution reaction, and a mechanistic insight in to the phenomenon is provided. ${ }^{15} \mathrm{~N}_{2}$ assisted labeling experiments are also conducted to confirm the formation of ammonia via NRR. This study opens up the possibilities of developing economically feasible electrodes for electrochemical NRR at lower energies with only transient modifications of electrodes during the electrolysis, unlike the studies reported on complex electrodes or electrolytes designed for NRR in aqueous medium to suppress the hydrogen generation.
\end{abstract}

Keywords: Nitrogen Reduction Reaction; Ammonia synthesis; Electrochemistry; Aqueous Electrolysis; Ambient Conditions. 


\section{Introduction:}

The conversion of nitrogen present in the atmosphere to fertilizers has enabled addressing the massive global food requirements, otherwise the planet couldn't have supported this ${ }^{1}$. This requires huge production of ammonia ( 188 million tons of ammonia $\left(\mathrm{NH}_{3}\right)$ by 2018$)^{2}-\mathrm{a}$ feedstock for fertilizers, and the process consumes $\sim 5 \%$ world's natural gas along with the enormous expulsion of $\mathrm{CO}_{2}$. Since $\mathrm{N} \equiv \mathrm{N}$ bond in the di-nitrogen is one of the strongest chemical bonds in nature $\left(225 \mathrm{kcal} \mathrm{mol}^{-1}\right)^{3}$, the $\mathrm{N}_{2}$ reduction resulting to ammonia production in ambient mild conditions is identified as a challenge ${ }^{4}$. The major ammonia production happening today is via Haber-Bosch method, which requires high temperature $\left(500^{\circ} \mathrm{C}\right)$ and pressure $(150-300$ bars) in presence of an efficient catalyst ${ }^{5,6}$. The enormous cost of this process along with unavoidable $\mathrm{CO}_{2}$ emission demand alternate methods for ammonia production, and various such methods have been attempted in the recent past to make the process in ambient conditions with a limited success (room temperature and atmospheric pressure) ${ }^{7-9}$. After being identified as a futuristic fuel, ammonia is recognized as a promising liquid $\mathrm{H}_{2}$ carrier due to its high hydrogen density (high gravimetric hydrogen density $(17.6 \mathrm{wt} \%)^{10}$ ). Further, ammonia can also be liquefied easily, ensuring its easy transport as a high gravimetric and volumetric energy capacity fuel ${ }^{11}$. Hence apart from its usage as a raw material for fertilizers, ammonia can also be envisaged as a feedstock for $\mathrm{H}_{2}$ based renewable carbon free energy resources ${ }^{10}$.

The intensive energy requirement for Haber-Bosch process initiated the search for alternative methods, where the hunt was for catalysts which break di-nitrogen triple bond and make ammonia when fed electricity ${ }^{12-14}$. During the last few years, several such approaches were pursued to reduce nitrogen electro-catalytically with varying electro-catalysts and electrolytes such as solid electrolytes ${ }^{15,16}$, organic ${ }^{17}$, ionic liquids ${ }^{18}$, molten salt ${ }^{13,19,20}$, aqueous electrolyte under ambient ${ }^{4,21}$ or high pressure ${ }^{22}$ conditions. But it was found that, even the best such catalyst (particularly those reported ambient conditions in aqueous conditions) can use only $1 \%$ of electrons forming ammonia due to the competitive other reactions such as hydrogen generation (in aqueous medium). The first report on the room temperature ammonia synthesis was based on the reduction of ligating molecular nitrogen, where the ammonia production occurs when compounds of the type $\mathrm{M}\left(\mathrm{N}_{2}\right)_{2}\left(\mathrm{PR}_{3}\right)_{4}(\mathrm{M}=\mathrm{Mo}$ or $\mathrm{W})$ treated at room temperature with sulfuric acid in methanol solution ${ }^{23}$. In this reduction mechanism, the metal must increase its oxidation 
states by six units and all the six electrons will be fed to the ligating nitrogen molecule, and such a great jump in oxidation state is highly likely impossible in simple catalytic systems and nitrogenase enzymes ${ }^{23}$. Further to this report, a few other reports were appeared for ammonia production in mild conditions, but using complex intermediates ${ }^{24}$.

Development of aqueous electrolytes-based strategy (other than molten salt or ionic liquid-based electrolysis) will benefit the implementation of this technology for commercial level ammonia production, and for which, electrodes are also needed to be simple and scalable in nature - unlike the reported complex catalysts. The highest yield reported so far for ambient condition aqueous based electro-catalytic ammonia production is 11\% (Faradaic Efficiency $(\% \mathrm{FE}))$ with very high over potential of $-1.19 \mathrm{~V} v s$. reverse hydrogen electrode (RHE), where Song et al. used nitrogen doped carbon nanospikes as electrodes which help to enhance the local electric field at the tip texture ${ }^{25}$.

It is known that certain alkali metal ions play interesting roles in a few electro-catalytic reactions $^{26-28}$. For example, the hydration sheath of alkali metal ions control the $\mathrm{pH}$ at the electrode interface which governs the concentration of $\mathrm{CO}_{2}$ in $\mathrm{CO}_{2}$ reduction reaction near to the electrode ${ }^{29}$. It is also reported that $\mathrm{Li}^{+}$ions can destabilize the water molecule and hence it can promote the rate of water splitting ${ }^{30}$. A study by Joshua M. McEnaney et. al. had shown that lithium can be electro-cycled to produce ammonia in molten electrolyte under atmospheric pressure with a very high $\% \mathrm{FE}$ of $88.5 \%{ }^{31}$. The studies show that $\mathrm{Li}^{0}$ can promote the electrochemical reduction of $\mathrm{N}_{2}$ to ammonia, where the applied energy (potential) needs to be higher so that electrodeposition of $\mathrm{Li}$ has to happen at the cathode which stabilizes nitrogen in the form of $\mathrm{Li}_{3} \mathrm{~N}^{30}$. Previously, Akira Tsuneto et. al. has obtained a $\% \mathrm{FE}$ of $57.7 \%$ on $\mathrm{Fe}$ electrode in $0.2 \mathrm{M} \mathrm{LiClO}_{4}$ in tetrahydrofuran (THF) as electrolyte with $0.18 \mathrm{M}$ ethanol as proton source under high pressure (50 atm) of $\mathrm{N}_{2}{ }^{17}$. Recently, the authors have studied the effect of concentration of $\mathrm{Li}^{+}$ions on the hydrogen evolution reaction (HER) in different metal surfaces, and interestingly $\mathrm{Li}^{+}$ion is found to be suppressing the HER on Pt surfaces whereas $\mathrm{Li}^{+}$promotes the HER activity of gold ${ }^{32}$, which is contrary to the Liumin Suo et al.'s report where the suppression of HER is attributed to the decomposition of TFSI $^{-}$anion in Lithium bis(trifluoromethanesulfonyl)imide (LiTFSI) salt forming LiF, which further blocks the transport of $\mathrm{H}^{+}$ions to the cathode ${ }^{33}$. Reducing nitrogen to ammonia electrochemically under ambient 
conditions in aqueous electrolyte is challenging due to the poor selectivity of electrodes towards nitrogen reduction ${ }^{10,34}$. In aqueous electrolytes, $\mathrm{N}_{2}$ reduction reaction is accompanied by HER since the standard potential required for nitrogen reduction reaction (NRR) is very much close to that of $\mathrm{HER}^{35}$. More kinetically facile proton reduction often outperforms electrochemical reduction of nitrogen to ammonia in aqueous medium. Hence methods are needed to be developed, those either suppress HER by modifying electro-catalysts having weak $\mathrm{H}^{+}$adsorption $^{36}$ or by limiting the availability of protons by modifying electrolyte (example: nonaqueous) $)^{37}$.

Here we report a different approach where the reduction of $\mathrm{N}_{2}$ to ammonia $\left(\mathrm{NH}_{3}\right)$ in ambient conditions is achieved with high concentration lithium salt containing aqueous electrolytes having high yield $(\% \mathrm{FE} \sim 12.1 \%)$ at low over potential $(\sim-0.6 \mathrm{~V}$ RHE or $-1.1 \mathrm{~V} v s$. $\mathrm{Ag} / \mathrm{AgCl}$ ). The influence of cations like $\mathrm{Li}^{+}$in NRR under these very low overpotentials is not explored so far in the literature, though some of these studies used Li based electrolytes for NRR ${ }^{38-40}$ Copper $(\mathrm{Cu})$ plate is used as the electro-catalyst for electrochemical reduction of $\mathrm{N}_{2}$. Recently, $\mathrm{Cu}$ is identified as one of the metals available in low price (lower than $\mathrm{Au}, \mathrm{Pt}, \mathrm{Pd}, \mathrm{Ag}$, $\mathrm{Co}$, and $\mathrm{Ni}$ ) while existing reasonably high level concentrations in ore ${ }^{41}$. Our recent observation on the tunability of the HER of $\mathrm{Pt}$ and $\mathrm{Au}$ with high concentration of $\mathrm{Li}^{+}$supporting electrolytes (LiTFSI and $\mathrm{LiClO}_{4}$ ) motivated the viability of such methods for NRR. Pt surface is highly active towards HER while $\mathrm{Au}$ and $\mathrm{Cu}$ surfaces are relatively less HER active ${ }^{42}$. The $\mathrm{Li}^{+}$source in this study is $\mathrm{LiClO}_{4}$ salt, where our previous study shows that $\mathrm{LiClO}_{4}$ and $\mathrm{LiTFSI}$ have similar effects on the HER activity of Au surfaces ${ }^{32}$.

\section{Results and Discussion:}

\subsection{Electrocatalytic reduction of $\mathrm{N}_{2}$ to $\mathrm{NH}_{3}$ :}

The details of the electrochemical cell (three electrode cell) set up are given in the supporting information. Two kinds of cells are being used. For LSV measurements, a three electrodes cell set up is used with $\mathrm{Cu}$ as working electrode, $\mathrm{Pt}$ as counter electrode, and $\mathrm{Ag} / \mathrm{AgCl}$ as reference electrode. Further, a two-compartments cell separated by a Nafion-117 membrane is used for electrochemical measurements to quantify the produced ammonia (figure S1). The electrochemical studies were conducted with graphite counter electrode too (in three-electrode 
cell set up) and the results were compared with that of Pt counter electrode (figure S2). The results show similar LSVs indicating the absence of any $\mathrm{Pt}$ influence in the observed phenomenon. Figure 1 shows the linear sweep voltammograms (LSVs) of $\mathrm{Cu}$ in $2.5 \mathrm{M} \mathrm{LiClO}_{4}$ solution saturated with $\mathrm{Ar}$ and $\mathrm{N}_{2}$ gases (30 min purging).

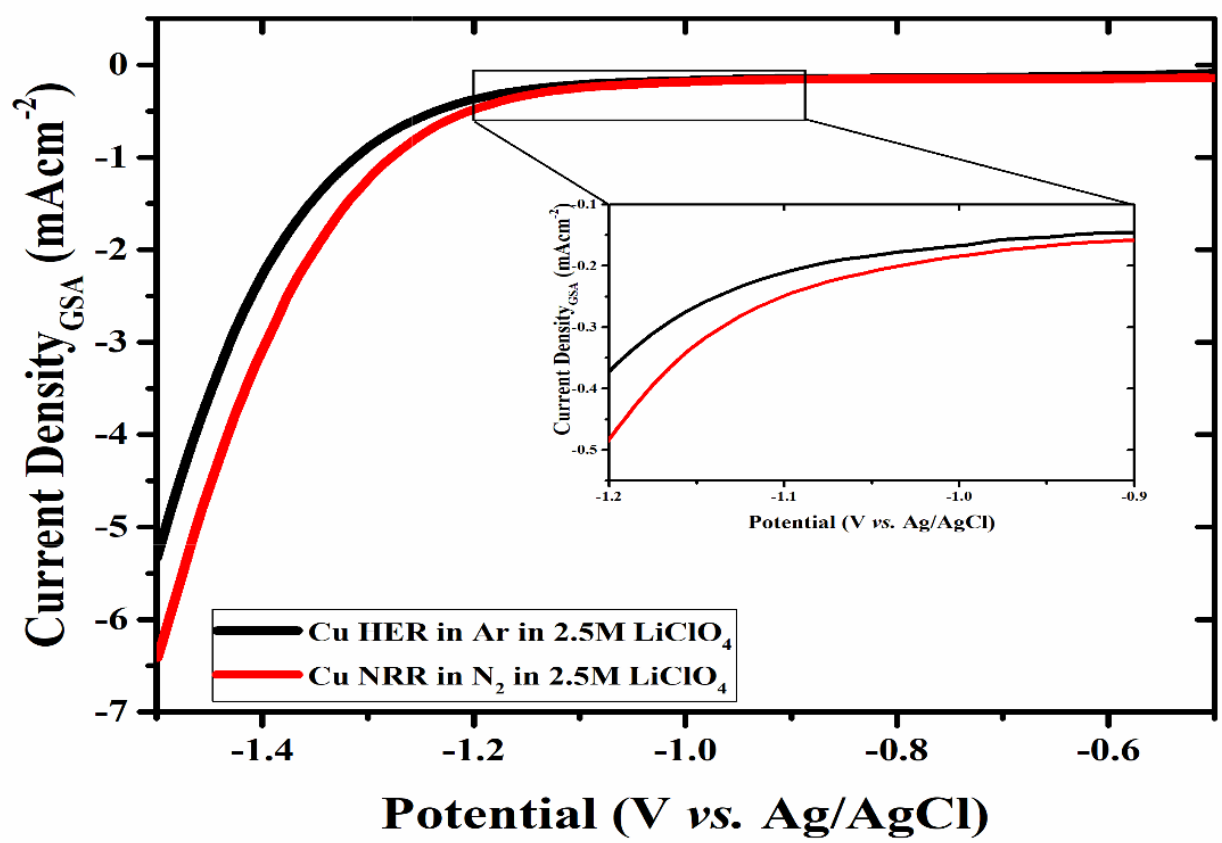

Figure 1: $\mathrm{LSV}_{\mathrm{s}}$ using $\mathrm{Cu}$ electrode in $2.5 \mathrm{M} \mathrm{LiClO}_{4}$ at $50 \mathrm{mV} / \mathrm{s}$ scan rate in argon(Ar) and nitrogen $\left(\mathrm{N}_{2}\right)$ saturated electrolytes (zoomed in onset potentials are shown in inset). The current density is calculated based on geometrical surface area (GSA, details are given in the supporting information).

The faradaic current at an onset potential of $\sim-1.1 \mathrm{~V}(\mathrm{Ag} / \mathrm{AgCl})$ for $\mathrm{Ar}$ saturated electrolyte shows the generation of hydrogen via HER. This onset potential is in tune with the reported values of HER onset potential of $\mathrm{Cu}^{43}$. Upon purging $\mathrm{N}_{2}$ - another inert gas, the onset potential is shifted slightly to a lower value $(-1.02 \mathrm{~V} v s . \mathrm{Ag} / \mathrm{AgCl})$ and an enhancement in the current density can be observed. This indicates an additional faradaic reaction happening with the $\mathrm{N}_{2}$ purging. To check the effect of this reaction with $\mathrm{Li}^{+}$concentrations, $\mathrm{LiClO}_{4}$ concentrations are varied from $0.1 \mathrm{M}$ to $5 \mathrm{M}$, and the corresponding LSVs are conducted (figure 2). The onset potential is found to be varying with respect to the concentration of $\mathrm{Li}^{+}$, where for $0.1 \mathrm{M} \mathrm{LiClO}_{4}$ the onset is at $-1.15 \mathrm{~V}$ and it is reduced to $-1.0 \mathrm{~V} v s$. $\mathrm{Ag} / \mathrm{AgCl}$ in $5 \mathrm{MLiClO}_{4}$. In 
our earlier study on the effect of $\mathrm{Li}^{+}$concentration on HER at Pt and Au surfaces, we have observed an enhancement in HER activity of Au with respect to the concentration of $\mathrm{Li}^{+}{ }^{32} \mathrm{In}$ this case, since the onset potential is less cathodic for $\mathrm{N}_{2}$ saturated electrolytes than Ar saturated electrolytes(figure1), it is clear that the change in onset potential with respect to the concentration of $\mathrm{Li}^{+}$is not due to the enhancement of HER activity (LSVs of $\mathrm{Cu}$ in $0.1 \mathrm{M}$ to $5 \mathrm{M}$ $\mathrm{LiClO}_{4}$ in $\mathrm{Ar}$ is shown in figure S2), and which is further verified via quantification of the NRR product.

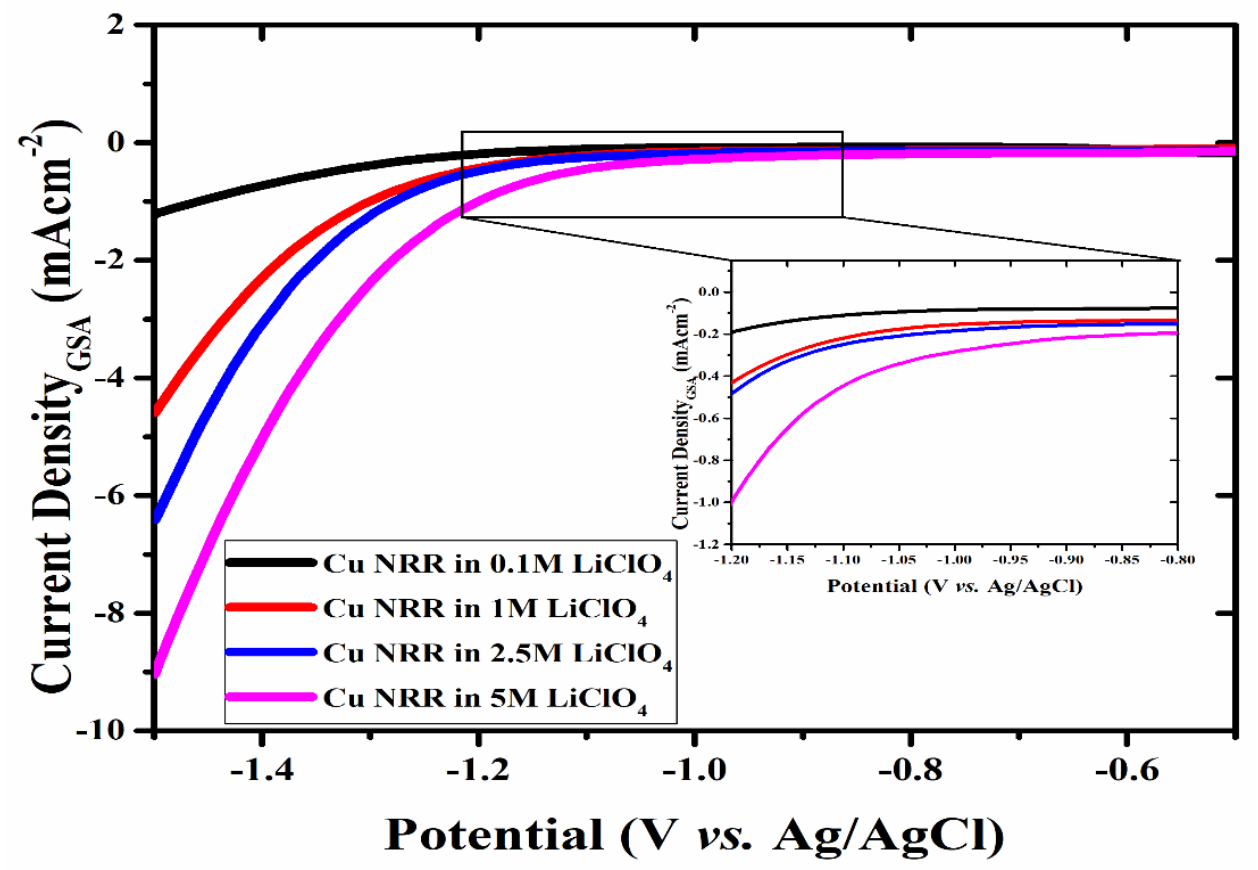

Figure 2: $\mathrm{LSVs}$ using $\mathrm{Cu}$ electrode at $50 \mathrm{mV} / \mathrm{s}$ scan rate in different concentrations of $\mathrm{LiClO}_{4}$ (zoomed in onset potentials are given in inset).

\subsection{Detection of $\mathrm{NH}_{3}$ :}

To further confirm the electrochemical reduction of $\mathrm{N}_{2}$, constant potential electrolysis (chronoamperometry) was carried out at different concentrations of $\mathrm{LiClO}_{4}$ starting from $0.1 \mathrm{M}$ to $5 \mathrm{M}$ at $-1.1 \mathrm{~V}$ with respect to $\mathrm{Ag} / \mathrm{AgCl}$. Similar to the $\mathrm{LSV}$ results (figure 2), amperometric current densities are increased from -0.07 to $-0.3 \mathrm{~mA} \cdot \mathrm{cm}_{\mathrm{GSA}}{ }^{-2}$ at $-1.1 \mathrm{~V}$ vs. $\mathrm{Ag} / \mathrm{AgCl}$ while increasing the concentration of $\mathrm{LiClO}_{4}$ from $0.1 \mathrm{M}$ to $5 \mathrm{M}$ (figure 3). After the electrolysis (for 30 minutes), an aliquot of electrolyte was collected for the product analysis. The presence of 
plausible NRR products namely ammonia and hydrazine were tested via different methods. These methods are namely- i) Nessler's reagent ${ }^{44}$, ii) Indophenol method ${ }^{45}$ iii) ${ }^{1} \mathrm{H} \mathrm{NMR}^{46}$ (those are for ammonia confirmatory), and, iv) N,N - dimethylamino benzaldehyde method for hydrazine ${ }^{47}$. Positive results were found for Nessler's reagent test (the color change from colorless to brown (result not shown)), Indophenol test (ammonia first reacts with $\mathrm{NaClO}$ to produce $\mathrm{NH}_{2} \mathrm{Cl}$ which further reacts with two salicylate molecules simultaneously to form 4-(4hydroxyphenyl)iminocyclohexa-2,5-dien-1-one, which is commonly known as 'Indophenol' having a color of blue but the solution color is green due to yellow color of sodium nitroferricyanide (figure 4 and S3) $)^{25,31}$ - indicating the formation of ammonia. The control experiments with known amount of ammonium ions are conducted and linearity of this sensing technique in the entire concentration region is also ensured (figure $\mathrm{S} 4, \mathrm{~S} 5, \mathrm{~S} 6, \mathrm{~S} 7$ and, S8). ${ }^{1} \mathrm{H}$ NMR study is also conducted on the electrolytes collected after 30 minutes of electrolysis with $\mathrm{N}_{2}$ purging in $5 \mathrm{M} \mathrm{LiClO}_{4}$ at $-1.1 \mathrm{~V} v s$. $\mathrm{Ag} / \mathrm{AgCl}$ and the data is shown in figure $\mathrm{S} 9$. The analyses show the presence of ammonia as a result of $\mathrm{N}_{2}$ reduction only (figure $\mathrm{S} 9$, and a detailed procedure is provided in supporting information). The electrolyte before the electrolysis indicates the absence of ammonia indicating the absence of any form of contamination from the electrolyte. Further confirmation of the NRR process is obtained from the ${ }^{15} \mathrm{~N}_{2}$ assisted ${ }^{1} \mathrm{H}$ NMR labeling experiments. Since ${ }^{15} \mathrm{~N}_{2}$ is expensive (Sigma Aldrich ${ }^{15} \mathrm{~N}_{2}$ 364584-250ML, figure S10A), the labeling experiment is conducted in a single compartment cell (air tightened cell which is initially saturated with argon followed by NRR as discussed in the following statements, figure S10B) after saturation with ${ }^{14} \mathrm{~N}_{2}$ and/or also using the mixture of ${ }^{14} \mathrm{~N}_{2}$ and ${ }^{15} \mathrm{~N}_{2}$ by purging the ${ }^{15} \mathrm{~N}_{2}$ directly to the electrolyte, and the electrolysis is performed up to 24 hour (h) at $-1.1 \mathrm{~V}$ vs. $\mathrm{Ag} / \mathrm{AgCl}$ using $\mathrm{Cu}$ electrode. Before the NRR, the ${ }^{1} \mathrm{H}$ NMR of the electrolyte is performed after saturating with the mixture of ${ }^{14} \mathrm{~N}_{2}$ and ${ }^{15} \mathrm{~N}_{2}$ to identify the possible ${ }^{15} \mathrm{~N}$ containing ammonia (as a contaminant) from the gas used. ${ }^{48} \mathrm{No}^{15} \mathrm{NH}_{4}{ }^{+}$peak was detected from the high resolution NMR analyses (6000 scan), which confirms that the ${ }^{15} \mathrm{~N}_{2}$ cylinder has no ${ }^{15} \mathrm{NH}_{4}{ }^{+}$contamination. When the electrolyte was saturated with only ${ }^{14} \mathrm{~N}_{2}$, no ${ }^{15} \mathrm{NH}_{4}{ }^{+}$peak is detected after 24 hour electrolysis (figure S11C) but both ${ }^{14} \mathrm{NH}_{4}{ }^{+}$and ${ }^{15} \mathrm{NH}_{4}{ }^{+}$peaks are detected after both 19 hour (figure S11D) and 24 hour (figure S11E) experiments, when the electrolyte was saturated with the mixture of ${ }^{14} \mathrm{~N}_{2}$ and ${ }^{15} \mathrm{~N}_{2}$, as explained before. The intensity (NMR) of ${ }^{15} \mathrm{NH}_{4}{ }^{+}$peak obtained after 19 hour experiment is lower than that of after 24 hour, confirming 
that the ammonia is not the result of any other contamination while solely coming from the NRR process. All these experiments confirm the NRR process of the purged $\mathrm{N}_{2}$ gas happening at the electrode surface.

Further for testing the presence of hydrazine, absence of any characteristic color (absorption at $460 \mathrm{~nm})^{47}$ change in $\mathrm{N}, \mathrm{N}$ - dimethyl amino benzaldehyde test giving the evidence for the absence of hydrazine (figure S12). These results suggest that ammonia is the sole product formed during $\mathrm{N}_{2}$ reduction. Further, control experiments were conducted in the absence of $\mathrm{N}_{2}$ (electrolysis with purging Ar) and also without applying any potential while saturated electrolyte with $\mathrm{N}_{2}$ for 30 minutes, as shown in figure $\mathrm{S} 13$. The results indicate the absence of ammonia formation suggesting that the formation of ammonia through electrochemical $\mathrm{NRR}$ on $\mathrm{Cu}$ electrode in high concentration of $\mathrm{LiClO}_{4}$.

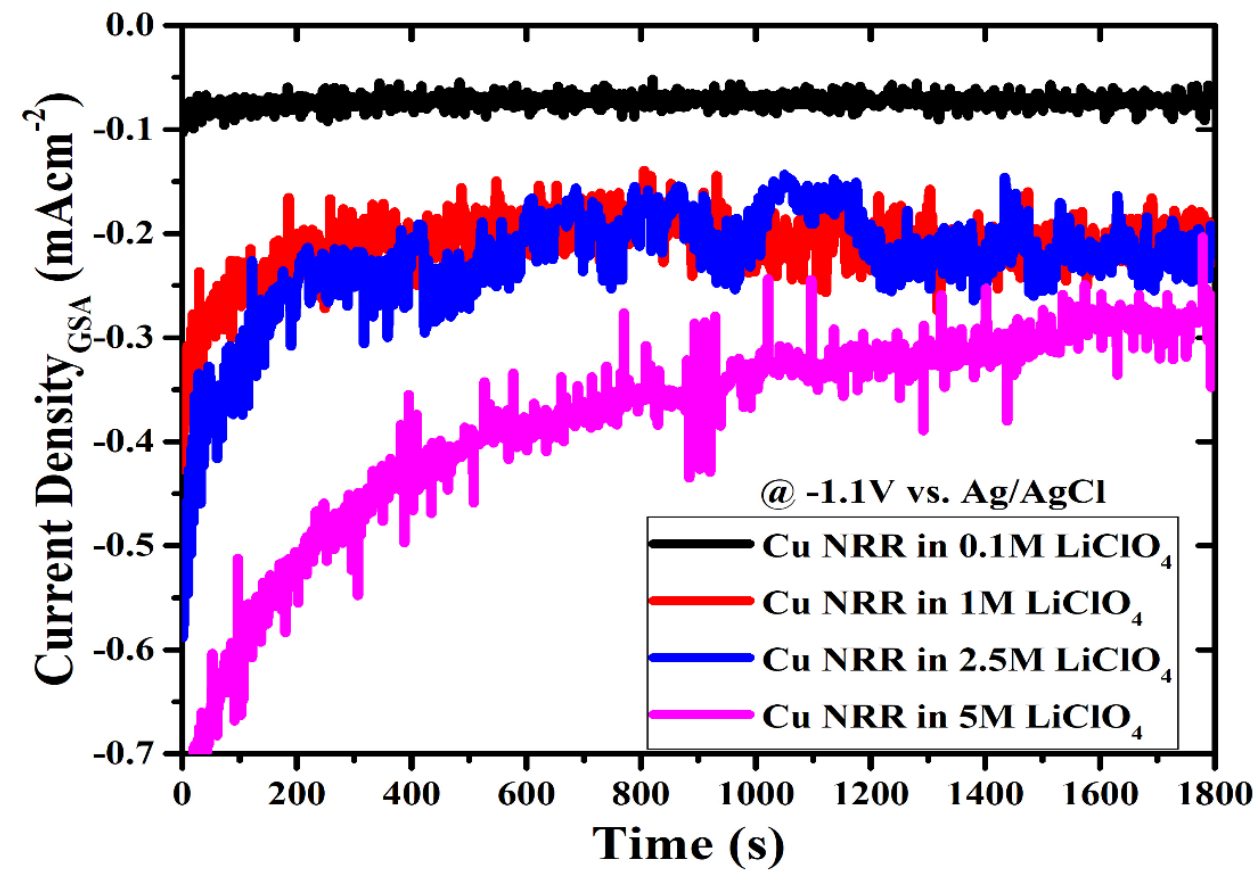

Figure 3: Chronoamperometry of $\mathrm{Cu}$ at $-1.1 \mathrm{~V} v s . \mathrm{Ag} / \mathrm{AgCl}$ for 30 minutes (mins) in different $\mathrm{LiClO}_{4}$ concentration. The longer time electrolysis data is given in the supporting information. [The stability of the catalyst for longer time 18 hours is shown in the supporting information]

In order to verify the role of $\mathrm{Li}^{+}$in NRR, the electrochemical experiments were carried out with $\mathrm{NaClO}_{4}$ as supporting electrolyte too (figures S13, S14 and, S15). The results show the absence of any product indicating that anion $\left(\mathrm{ClO}_{4}^{-}\right)$plays insignificant role in this process. Further, at very low concentrations of $\mathrm{Li}^{+}$, NRR product formation is not observed (figure S3). 
Figure S14 indicates that the HER on $\mathrm{Cu}$ is also slightly augmented with $\mathrm{Li}^{+}$, as we observed in Au in our previous study. ${ }^{32}$ These studies show that electrochemical NRR at ambient conditions take place only in reasonably high concentration of $\mathrm{Li}^{+}$ions.

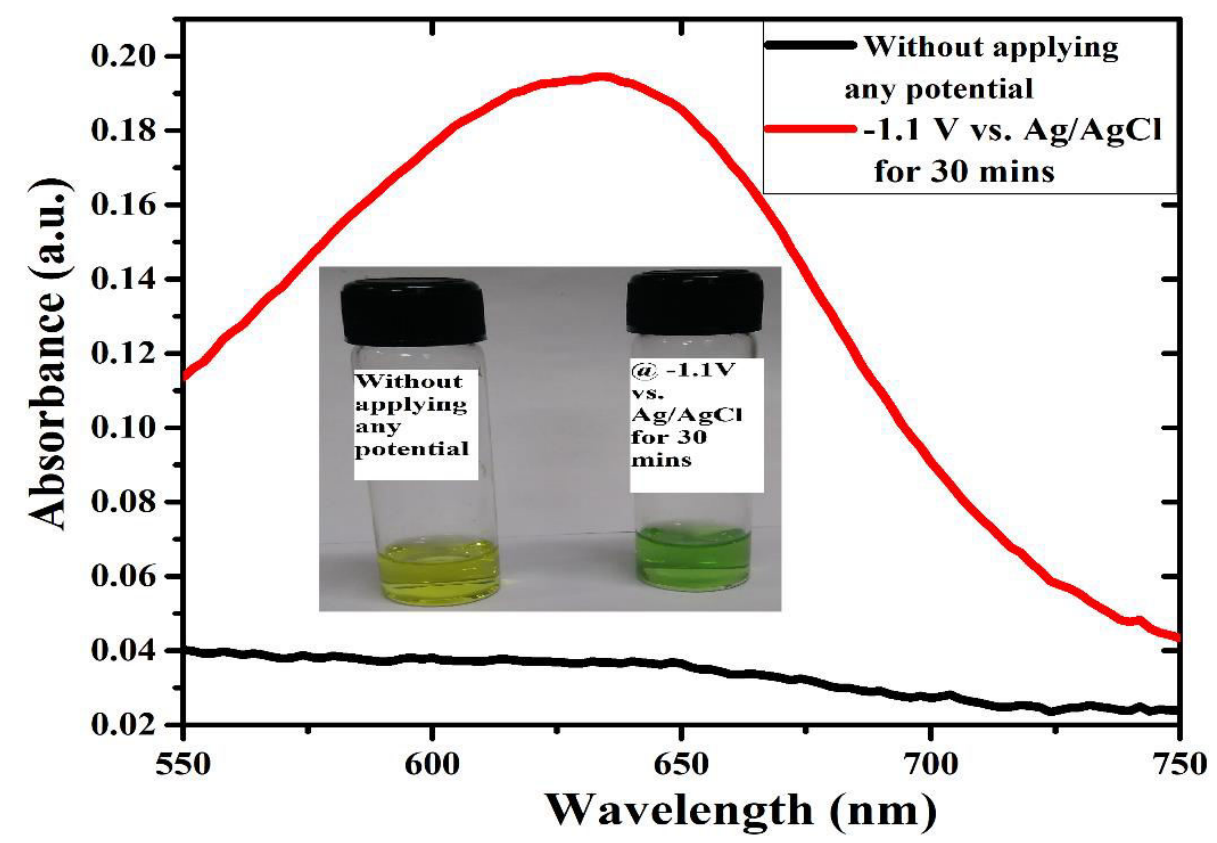

Figure 4: Absorption spectra of the NRR products (collected after $30 \mathrm{~min}$ of chronoamperometry) conducted using $\mathrm{Cu}$ electrode in $5 \mathrm{M} \mathrm{LiClO}_{4}$ electrolyte without applying potential (black) and applying -1.1V vs. $\mathrm{Ag} / \mathrm{AgCl}$ (red) (Inset: photographs of the NRR product collected after Indophenol test - without applying any potential (yellow) and applying potential

$$
-1.1 \mathrm{~V}(\text { green })) \text {. }
$$

\subsection{Quantification of $\mathrm{NH}_{3}$ :}

The 'Indophenol method' is used to quantify the ammonia formed to calculate \%FE (details are given in the supporting information), since it is sensitive enough for 'sub-ppm' level of ammonia (figure 4). ${ }^{45}$ It is found that no ammonia was formed at $0.1 \mathrm{M}$ and $1 \mathrm{M} \mathrm{LiClO}_{4}$ concentrations at $-1.1 \mathrm{~V}$ vs. $\mathrm{Ag} / \mathrm{AgCl}$ applied potential based electrolysis (figure $\mathrm{S} 3$ ). Small amount of ammonia is detected with a rate of formation of ammonia of $\sim 5.25 \pm 2.05 \times 10^{-}$ ${ }^{11}$ mole. ${ }^{-1} \cdot \mathrm{cm}_{\mathrm{GSA}}{ }^{-2}$ and $5.6 \pm 2.2 \% \% \mathrm{FE}$ when the concentration was raised to $2.5 \mathrm{M} \mathrm{LiClO}_{4}$ (details of rate and $\mathrm{FE} \%$ calculations are given in supporting information). But the highest \% FE 
i.e. $(12.1 \pm 0.8) \%$ and highest rate of production i.e. $(19.7 \pm 3.9) \times 10^{-11}$ mole.s $^{-1} \cdot \mathrm{cm}_{\mathrm{GSA}}{ }^{-2}$ are observed when $5 \mathrm{M} \mathrm{LiClO}_{4}$ was used as electrolyte at $-1.1 \mathrm{~V} v s$. $\mathrm{Ag} / \mathrm{AgCl}$ (figures $5 \mathrm{~A}, 5 \mathrm{C}$, and S3). Hence it can be concluded that while increasing the $\mathrm{Li}^{+}$concentration, the rate and $\% \mathrm{FE}$ of ammonia formation increases. Similar thing happened with $\mathrm{Au}$ as working electrode too, there while varying the $\mathrm{LiClO}_{4}$ concentrations from $1 \mathrm{M}$ to $5 \mathrm{M}$, the rate and $\% \mathrm{FE}$ are found to be enhanced though the values are inferior to that on $\mathrm{Cu}$ electrode(table 1 and, figure S16 and, S17). The lower NRR values on Au electrode might be due to the fact that the HER is more pronounced in $\mathrm{Au}$ than $\mathrm{Cu}$, as it is reported by other researchers ${ }^{49}$.

To optimize the overpotential further, the electrochemical conditions of $\mathrm{Cu}-5 \mathrm{M} \mathrm{LiClO} 4$ system is varied - where chronoamperometry is conducted in different potentials $(-1.0 \mathrm{~V}$ to $-1.2 \mathrm{~V} v s$. $\mathrm{Ag} / \mathrm{AgCl}$ ). It is observed that, when the overpotential was $-1.1 \mathrm{~V}$, maximum $\% \mathrm{FE}$ and the rate of ammonia formation (i.e. $12.1 \pm 0.8 \%$ and $19.7 \pm 3.9 \times 10^{-11}$ mole. $\mathrm{s}^{-1} \cdot \mathrm{cm}_{\mathrm{GSA}}{ }^{-2}$ respectively) are observed. The rest of the $\% \mathrm{FE}$ is for hydrogen production, since no other product is obtained after NRR except $\mathrm{H}_{2}$. On the other hand, while the over potential was lower or higher than $-1.1 \mathrm{~V}$, lesser amount of ammonia is found to be formed (figure 5B, 5D, S18 and S19). For example, at $-1.0 \mathrm{~V}$, the $\% \mathrm{FE}$ and rate of ammonia formation are calculated as $\sim 2.01 \%$ and $\sim 1.83 \times 10^{-11}$ mole. $\mathrm{s}^{-1} \cdot \mathrm{cm}_{\mathrm{GSA}}{ }^{-2}$, respectively, and those at $-1.2 \mathrm{~V}$ rate are found to be $0.45 \%$ and $2.33 \times 10^{-11}$ mole. $\mathrm{s}^{-1} \cdot \mathrm{cm}_{\mathrm{GSA}}{ }^{-2}$, respectively. Lowering the NRR product at higher potentials $(>-1.1 \mathrm{~V} v s . \mathrm{Ag} / \mathrm{AgCl})$ is due to the enhanced HER which always competes with NRR. This is further confirmed by the very low $\% \mathrm{FE}$ of $0.08 \%$ when NRR is performed at $-1.4 \mathrm{~V} v s$. $\mathrm{Ag} / \mathrm{AgCl}$. The chronoamperometry study in $\mathrm{N}_{2}$ saturated $5 \mathrm{M} \mathrm{LiClO}_{4}$ is performed for 18 hours (h) to confirm the stability of the electrocatalyst in the electrolyte - which is shown in figure S20. The indophenol test is also performed at different time intervals, which is shown in figure S21. This is suggesting that the amount of produced ammonia is linearly increasing with time. 

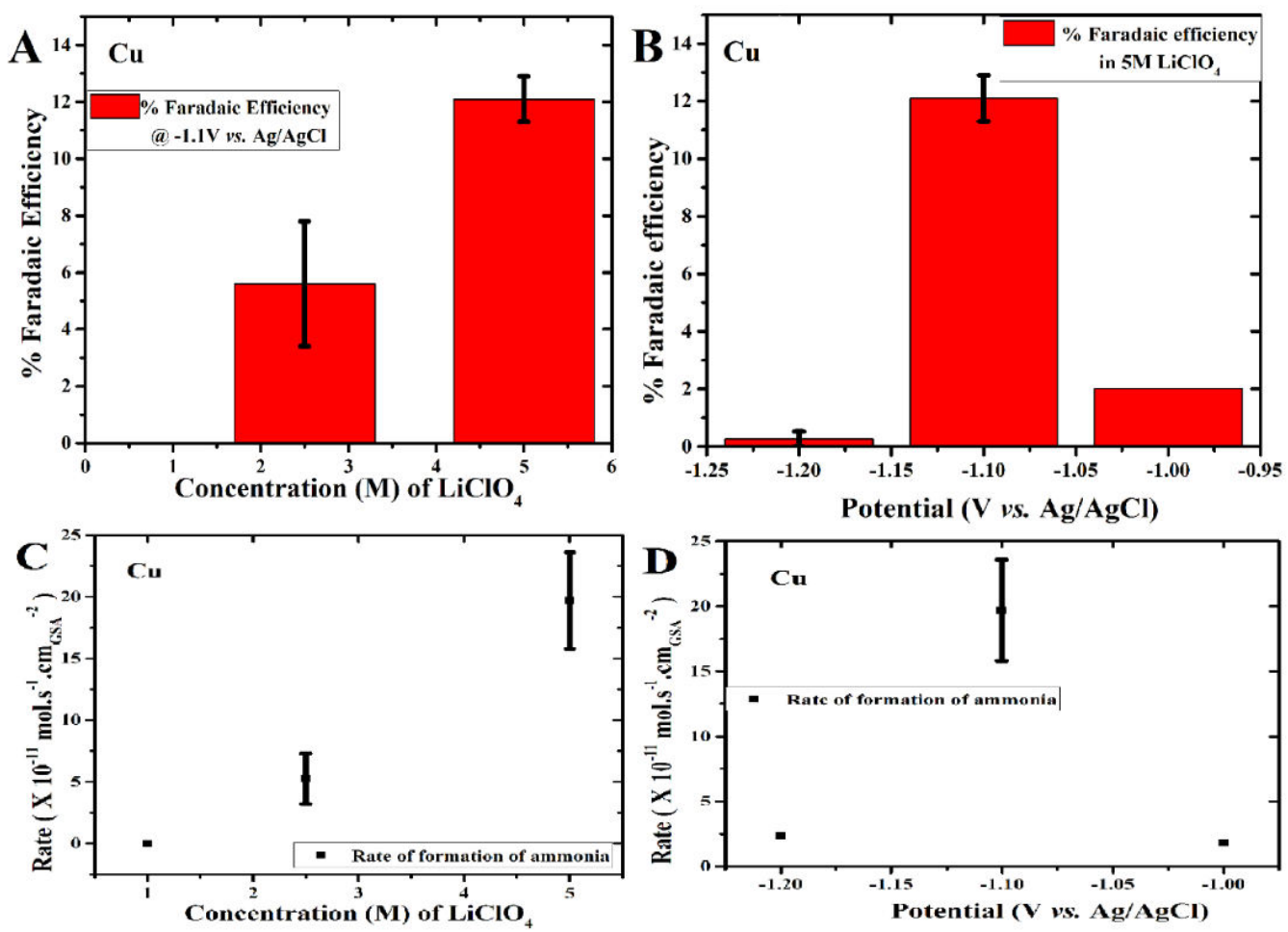

Figure 5:A) Faradaic efficiency vs. concentration of $\mathrm{LiClO}_{4} \mathrm{at}-1.1 \mathrm{~V} v s$. $(\mathrm{Ag} / \mathrm{AgCl})$ in $\mathrm{N}_{2}$ atmosphere, B) Faradaic efficiency vs. potential $(\mathrm{Ag} / \mathrm{AgCl})$ in $\mathrm{N}_{2}$ atmosphere at $\left.5 \mathrm{M} \mathrm{LiClO}_{4}, \mathrm{C}\right)$ Rate of ammonia formation $v s$. concentration of $\mathrm{LiClO}_{4}$ at $-1.1 \mathrm{~V} v s$. $\mathrm{Ag} / \mathrm{AgCl}$ in $\mathrm{N}_{2}$ atmosphere, D) Rate of ammonia formation $v s$. potential $(v s . \mathrm{Ag} / \mathrm{AgCl})$ in $\mathrm{N}_{2}$ atmosphere at $5 \mathrm{M} \mathrm{LiClO}_{4} \cdot \mathrm{Cu}$ is used as working electrode in all the cases.

\begin{tabular}{|c|c|c|c|c|}
\hline $\begin{array}{l}\text { Electrode } \\
(-1.1 \mathrm{~V} v s . \\
\text { Ag/AgCl })\end{array}$ & Electrolyte & $\begin{array}{c}\text { Concentratio } \\
\text { n of } \\
\mathrm{NH}_{3}(\mu \mathrm{mol} / \mathrm{L})\end{array}$ & $\begin{array}{c}\text { Rate of formation } \\
\text { of } \mathrm{NH}_{3} \\
\left(\mathrm{~mol}^{-1} \mathrm{~s}^{-1} \mathrm{~cm}_{\mathrm{GSA}}{ }^{-2}\right)\end{array}$ & $\begin{array}{c}\text { Faradaic Efficiency } \\
\text { (FE\%) }\end{array}$ \\
\hline$\overline{\mathrm{Cu}}$ & $1 \mathrm{M} \mathrm{LiClO}_{4}$ & Nil & Nil & Nil \\
\hline $\mathrm{Cu}$ & 2.5 $\mathrm{M} \mathrm{LiClO}_{4}$ & 9.18 & $5.25 \pm 2.05 \times 10^{-11}$ & $5.6 \pm 2.2 \%$ \\
\hline $\mathrm{Cu}$ & $5 \mathrm{M} \mathrm{LiClO}_{4}$ & 41.30 & $19.7 \pm 3.9 \times 10^{-11}$ & $12.1 \pm 0.8 \%$ \\
\hline Au & $1 \mathrm{M} \mathrm{LiClO}_{4}$ & Nil & Nil & Nil \\
\hline $\mathrm{Au}$ & $2.5 \mathrm{M} \mathrm{LiClO}_{4}$ & 3.48 & $1.4 \times 10^{-11}$ & $0.05 \%$ \\
\hline Au & $5 \mathrm{M} \mathrm{LiClO}_{4}$ & 28.53 & $11.8 \times 10^{-11}$ & $1.8 \%$ \\
\hline
\end{tabular}


Table 1: Concentration, rate of formation and faradaic efficiency of ammonia in different concentration of $\mathrm{LiClO}_{4}$ on $\mathrm{Cu}$ and $\mathrm{Au}$ electrode

\subsection{Mechanism:}

Two kinds of mechanisms were reported in literature for NRR to ammonia, namely, (a) associative mechanism in which triply bonded $\mathrm{N}_{2}$ gets adsorbed on the metal surface before hydrogenation occurs to give ammonia and (b) dissociative mechanism where triple bonded $\mathrm{N}_{2}$ dissociate to produce two $\mathrm{N}$ atoms, which further bind to metal surface and produce ammonia by hydrogenation. ${ }^{50}$ The dissociative mechanism is proposed to occur during Haber - Bosch process using transition metal surfaces at higher temperatures. ${ }^{25}$ But theoretical studies show that the dissociative mechanism cannot be taken place on metals like $\mathrm{Cu}$ under ambient conditions. ${ }^{35}$ Electrochemical reduction of $\mathrm{N}_{2}$ to ammonia in $\mathrm{Li}$ based molten electrolyte was studied by McEnaney et. al and they showed that under high applied potentials, $\mathrm{Li}^{+}$ions in the molten electrolyte get reduced to form metallic $\mathrm{Li}^{31}{ }^{31}$ This metallic $\mathrm{Li}$ reacts with the dissolved $\mathrm{N}_{2}$ to give $\mathrm{Li}_{3} \mathrm{~N}$, which further get oxidized to $\mathrm{Li}^{+}$and $\mathrm{NH}_{3}{ }^{31}$. Akira Tsuneto et. al has proposed a similar mechanism in non-aqueous electrolytes where $\mathrm{Li}^{+}$electrochemically reduced to $\mathrm{Li}$ which first reacts with $\mathrm{N}_{2}$ to give $\mathrm{Li}_{3} \mathrm{~N}$. $\mathrm{Li}_{3} \mathrm{~N}$ further gets oxidized to $\mathrm{Li}^{+}$and $\mathrm{NH}_{3}{ }^{17}$. In the present study, the electrochemical NRR is carried out in aqueous $\mathrm{LiClO}_{4}$ solutions under ambient conditions at much lower potentials (maximum applied potential of $-1.5 \mathrm{~V} v s$. $\mathrm{Ag} / \mathrm{AgCl}$ ) than that $\mathrm{of}^{+}$ reduction potential $(-3.25 \mathrm{~V}$ vs. $\mathrm{Ag} / \mathrm{AgCl})$ and hence possibilities of $\mathrm{Li}^{0}$ electrodeposition can be ruled out. This is further confirmed by the X-ray photoelectron spectroscopy (XPS) studies conducted on the $\mathrm{Cu}$ electrode after the reaction, the results of which are shown in figure S22-24. The XPS depth profiling is also carried out to probe the possibilities of intercalated $\mathrm{Li}$, and no such signal is observed indicating the role of $\mathrm{Li}^{+}$during the reaction is a completely transient one (the photographs of the $\mathrm{Cu}$ electrode before and after electrolysis are also provided in figure S25). Further, a partial oxidation of $\mathrm{Cu}$ surface is also evident from the XPS analyses, but this doesn't change the microstructure of the electrodes before and after NRR. Experiments were conducted by oxidizing $\mathrm{Cu}$ plate prior to NRR and conducting the electrochemical NRR in similar conditions $\left(5 \mathrm{M} \mathrm{LiClO}_{4}\right)$. The $\mathrm{Cu}$ plate after NRR did not show the presence of oxide or hydroxide layer indicating the role of $\mathrm{Cu}^{0}$ in NRR. 
In a recent report on the double layer (electric) capacitance of $\mathrm{Pt}$ and $\mathrm{Au}$ metals in presence of $\mathrm{CAClO}_{4}$ (where CA stands for $\mathrm{Li}^{+}$or $\mathrm{Na}^{+}$or $\mathrm{K}^{+}$or $\mathrm{Rb}^{+}$or $\mathrm{Cs}^{+}$), local (near electrode) effective concentrations of cations are found to be as high as $\sim 80$ times than that in their bulk solution ${ }^{51}$. Hence in concentrated $\mathrm{Li}^{+}$solutions, the effective $\mathrm{Li}^{+}$concentration in the double layer can be much higher than that in bulk solution for both $\mathrm{Pt}$ and $\mathrm{Au}$ electrodes (the experiments on $\mathrm{Cu}$ has yet to be conducted). In the present study, the $\mathrm{Na}^{+}$has not influenced the NRR even at high concentrations $\left(5 \mathrm{M} \mathrm{NaCLO}_{4}\right)$. It is reported that $\mathrm{N}_{2}$ gets strongly adsorbed on $\mathrm{Li}^{+}$containing surfaces ${ }^{5-54}$. This indicates that the plausible stabilization of large amount of $\mathrm{N}_{2}$ on $\mathrm{Cu}$ surface at high $\mathrm{Li}^{+}$concentrations is the mechanism leading to the high ammonia production in reasonably lower potentials (lowest ever reported). A density functional theory (DFT) based study is conducted to unravel this proposed mechanism and the details are mentioned below:

DFT based calculation (details of the calculation are given in the supporting information) is carried out to further investigate the mechanism of the electrochemical $\mathrm{N}_{2}$ reduction on $\mathrm{Au}$ and $\mathrm{Cu}$ surfaces. The prime objective of this set of calculations is to investigate the ability of $\mathrm{Li}^{+}$to dissociate $\mathrm{N}_{2}$ molecule on $\mathrm{Cu}$ and $\mathrm{Au}$ surfaces. Here 001 plane $((001))$ is chosen for both $\mathrm{Au}$ and $\mathrm{Cu}$. In the absence of $\mathrm{Li}^{+}$, (001) surfaces of both $\mathrm{Cu}$ and $\mathrm{Au}$ are unable to split the triple bonded $\mathrm{N}_{2}$ which is supported by the similar bond length between two $\mathrm{N}$ atoms (1.12 $\AA$ ) of a bridge resting $\mathrm{N}_{2}$ molecule on the $\mathrm{Cu} / \mathrm{Au}$ surface and an isolated $\mathrm{N}_{2}$ molecule (figure 6). $\mathrm{N}_{2}$ gets adsorbed more strongly on $\mathrm{Cu}$ surface than $\mathrm{Au}$ surface as binding energy on $\mathrm{Cu}\left(\Delta \mathrm{E}_{\mathrm{Cu}-\mathrm{N}_{2}}=\right)$ is found to be $-0.23 \mathrm{eV}$ and that of $\mathrm{Au}$ is $\left(\Delta \mathrm{E}_{\mathrm{Au}-\mathrm{N}_{2}}=\right)+0.23 \mathrm{eV}\left(\Delta \mathrm{E}_{\mathrm{Cu}-\mathrm{N}_{2}}\right.$ is adsorption energy of $\mathrm{N}_{2}$ on $\mathrm{Cu}$ and $\Delta \mathrm{E}_{\mathrm{Au}-\mathrm{N} 2}$ is adsorption energy of $\mathrm{N}_{2}$ on $\mathrm{Au}$, the values are without temperature corrected). On the other hand, in presence of $\mathrm{Li}^{+}$, the computed $\mathrm{N}-\mathrm{N}$ bond distance is found to be increased to $2.91 \AA$ from $1.12 \AA$ without $\mathrm{Li}^{+}$ions, (where $\mathrm{Cu}-\mathrm{N}$ bond distance becomes $1.09 \AA$ in comparison to its initial value (without $\mathrm{Li}^{+}$) $2.31 \AA$, figure 6). Hence it can be concluded that $\mathrm{Li}^{+}$is helping not only to adsorb $\mathrm{N}_{2}$ on $\mathrm{Cu}$ surface but also to dissociate the $\mathrm{N}-\mathrm{N}$ triple bond, which is the rate limiting step in the $\mathrm{N}_{2}$ reduction reaction. In the case of $\mathrm{Au}$ surface, the $\mathrm{N}-\mathrm{N}$ bond distance is found to be $1.12 \AA$ in the absence of $\mathrm{Li}^{+}$(similar to that on $\mathrm{Cu}$ ), whereas it is 1.6 $\AA$ with $\mathrm{Li}^{+}$. Hence the DFT calculations suggest that $\mathrm{Li}^{+}$stabilizes nitrogen near the $\mathrm{Cu} / \mathrm{Au}$ electrode and helps to dissociate the $\mathrm{N} \equiv \mathrm{N}$. These findings are in tune with the previous 
observations as it is mentioned in the previous paragraphs. ${ }^{47-50}$ Further, the destabilization of $\mathrm{N} \equiv \mathrm{N}$ (elongation of the bond length) is higher with $\mathrm{Cu}$ electrode (than $\mathrm{Au}$ ), and hence the $\mathrm{N}_{2}$ reduction on $\mathrm{Cu}$ is happening at low overpotential with high \%FE. Further, the elongation of the bond length in the presence of $\mathrm{Li}^{+}$also suggest the possible associative NRR mechanism as it is predicted for $\mathrm{Cu}$ in ambient conditions. ${ }^{34}$ The DFT calculations are also conducted with $\mathrm{LiCl}$ (not shown here) and similar results are obtained, indicating that anions have no or less role in this observed mechanism which is in tune with our experimental observations.

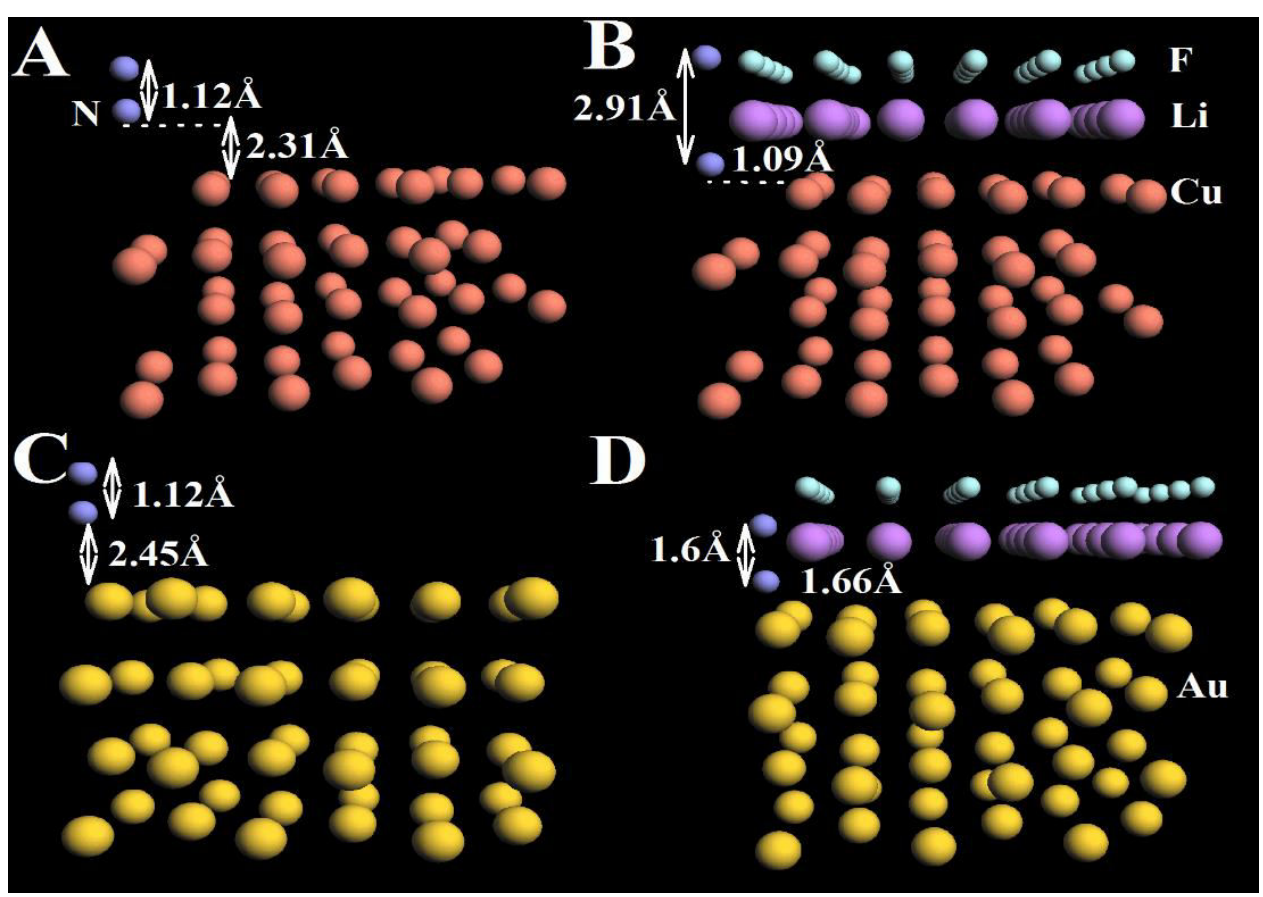

Figure 6: $\mathrm{N}_{2}$ adsorption on $\mathrm{Cu}(100)$ surface $A$ ) in absence and, B) in presence of LiF. $\mathrm{N}_{2}$ adsorption on $\mathrm{Au}(100)$ surface $\mathrm{A}$ ) in absence and B) in presence of LiF. The atoms are indicated by the following color coding: yellow - $\mathrm{Au}$, brown $-\mathrm{Cu}$, blue - nitrogen $(\mathrm{N})$, violet - Li, sea green - F.

\section{Conclusion:}

In conclusion, we report the highest yield ammonia production $(\% \mathrm{FE}=12.1 \pm 0.8 \%)$ via nitrogen reduction using ' $\mathrm{Li}^{+}$ions containing aqueous electrolysis in ambient conditions' with the aid of an otherwise (pristine form) inert electrode - polycrystalline copper. The product after NRR is found to be solely ammonia $\left(\mathrm{NH}_{3}\right)$. The formation of $\mathrm{NH}_{3}$ via $\mathrm{NRR}$ is confirmed using 
${ }^{15} \mathrm{~N}_{2}$ assisted labeling experiments. The $\mathrm{Li}^{+}$ions in high concentrations $(5 \mathrm{M}$, highest solubility for $\mathrm{LiClO}_{4}$ in aqueous medium) promotes the electrochemical $\mathrm{NRR}$ on $\mathrm{Cu}$ at lower over potentials $\left(-1.1 \mathrm{~V}\right.$ vs. $\mathrm{Ag} / \mathrm{AgCl}$ - lowest potential so far reported), while the $\mathrm{Li}^{+}$effect on $\mathrm{Cu}$ is found to be completely transient as no traces of $\mathrm{Li}^{+}$is observed after the reaction. The concentration (and rate of production in mol.s ${ }^{-1} \cdot \mathrm{cm}_{\mathrm{GSA}}{ }^{-2}$ ) of $\mathrm{NH}_{3}$ at $1 \mathrm{M}$ and $5 \mathrm{M} \mathrm{LiClO}_{4}$ concentrations are found to be zero $\left(\mu \mathrm{mol} / \mathrm{L}\right.$, rate is also $\left.0 \mathrm{~mol} \cdot \mathrm{s}^{-1} \cdot \mathrm{cm}_{\mathrm{GSA}}{ }^{-2}\right)$ and $\sim 41 \mu \mathrm{mol} / \mathrm{L}(\sim$ $20 \mathrm{X} 10^{-11} \mathrm{~mol} \cdot \mathrm{s}^{-1} \cdot \mathrm{cm}_{\mathrm{GSA}}{ }^{-2}$ ), respectively, indicating the role of $\mathrm{Li}^{+}$in electrochemical NRR, while no such effect is observed with $\mathrm{NaClO}_{4}$ based electrochemical NRR. The choice of electrode is made as $\mathrm{Cu}$ in this study due to its relatively lower price, large availability at earth crust, and less HER activity ${ }^{41,42}$. A similar phenomenon is found to exist for Au electrode too, while the yield of ammonia is found to be much lesser. The yield of ammonia production can be further enhanced with this new protocol while carefully selecting the electrode less prone to HER - such as iron $(\mathrm{Fe})$, which is further economically cheaper and high fraction is available in ores ${ }^{41}$.The observed augmented aqueous NRR on $\mathrm{Cu}$ with lithium containing salts-based electrolytes is verified by DFT based calculations. Such a transient modification of electrodes using available polycrystalline metallic surfaces without much prior modification can be a paradigm shift in the low energy ammonia production and ammonia based futuristic energetics.

\section{Supporting Information}

Supporting data available.

\section{Acknowledgments}

Authors thank Tata Institute of Fundamental Research, India for the financial support and the National Facility for High-Field NMR, TIFR, Hyderabad for the NMR facility. Authors thank Mr. Johnathan and Mr. Farhan Surve for XPS analyses using AXIS Supra (Kratos Analytical Shimazdu).

\section{References}

(1) Service, R. F. New Recipe Produces Ammonia from Air, Water, and Sunlight. Science (80). 2014, 345 (6197), 610.

(2) FAO. World Fertilizer Trends and Outlook to 2018. Food Agric. Organ. United Nations 
2015, 66 .

(3) Greschner, M. J.; Zhang, M.; Majumdar, A.; Liu, H.; Peng, F.; Tse, J. S.; Yao, Y. A New Allotrope of Nitrogen as High-Energy Density Material. J. Phys. Chem. A 2016, 120 (18), 2920-2925.

(4) Lan, R.; Irvine, J. T. S.; Tao, S. Synthesis of Ammonia Directly from Air and Water at Ambient Temperature and Pressure. Sci. Rep. 2013, 3, 1-7.

(5) Modak, J. M. Haber Process for Ammonia Synthesis. Resonance 2002, 7 (8), 69-77.

(6) Pool, J. A.; Lobkovsky, E.; Chirik, P. J. Hydrogenation and Cleavage of Dinitrogen to Ammonia with a Zirconium Complex. Nature 2004, 427 (6974), 527-530.

(7) Liu, C.; Sakimoto, K. K.; Colón, B. C.; Silver, P. A.; Nocera, D. G. Ambient Nitrogen Reduction Cycle Using a Hybrid Inorganic-biological System. Proc. Natl. Acad. Sci. 2017, 114 (25), 6450-6455.

(8) Hirakawa, H.; Hashimoto, M.; Shiraishi, Y.; Hirai, T. Photocatalytic Conversion of Nitrogen to Ammonia with Water on Surface Oxygen Vacancies of Titanium Dioxide. $J$. Am. Chem. Soc. 2017, 139 (31), 10929-10936.

(9) Bao, D.; Zhang, Q.; Meng, F.-L.; Zhong, H.-X.; Shi, M.-M.; Zhang, Y.; Yan, J.-M.; Jiang, Q.; Zhang, X.-B. Electrochemical Reduction of $\mathrm{N}_{2}$ under Ambient Conditions for Artificial $\mathrm{N}_{2}$ Fixation and Renewable Energy Storage Using $\mathrm{N}_{2} / \mathrm{NH}_{3}$ Cycle. Adv. Mater. 2017, 29 (3), 1604799.

(10) Shi, M.-M.; Bao, D.; Li, S.-J.; Wulan, B.-R.; Yan, J.-M.; Jiang, Q. Anchoring PdCu Amorphous Nanocluster on Graphene for Electrochemical Reduction of $\mathrm{N}_{2}$ to $\mathrm{NH}_{3}$ under Ambient Conditions in Aqueous Solution. Adv. Energy Mater. 2018, 1800124, 1800124.

(11) Hinokuma, S.; Kiritoshi, S.; Kawabata, Y.; Araki, K.; Matsuki, S.; Sato, T.; Machida, M. Catalytic Ammonia Combustion Properties and Operando Characterization of Copper Oxides Supported on Aluminum Silicates and Silicon Oxides. J. Catal. 2018, 361 (April), 267-277. 
(12) Chen, G.-F.; Cao, X.; Wu, S.; Zeng, X.; Ding, L.-X.; Zhu, M.; Wang, H. Ammonia Electrosynthesis with High Selectivity under Ambient Conditions via a $\mathrm{Li}^{+}$Incorporation Strategy. J. Am. Chem. Soc. 2017, 139 (29), 9771-9774.

(13) Licht, S.; Cui, B.; Wang, B.; Li, F. F.; Lau, J.; Liu, S. Ammonia Synthesis by $\mathrm{N}_{2}$ and Steam Electrolysis in Molten Hydroxide Suspensions of Nanoscale $\mathrm{Fe}_{2} \mathrm{O}_{3}$. Science (80). 2014, 345 (6197), 637-640.

(14) Chen, S.; Perathoner, S.; Ampelli, C.; Mebrahtu, C.; Su, D.; Centi, G. Room-Temperature Electrocatalytic Synthesis of $\mathrm{NH}_{3}$ from $\mathrm{H}_{2} \mathrm{O}$ and $\mathrm{N}_{2}$ in a Gas-Liquid-Solid Three-Phase Reactor. ACS Sustain. Chem. Eng. 2017, 5 (8), 7393-7400.

(15) Lan, R.; Tao, S. Electrochemical Synthesis of Ammonia Directly from Air and Water Using a Li${ }^{+} / \mathrm{H}^{+} / \mathrm{NH}_{4}{ }^{+}$Mixed Conducting Electrolyte. RSC Adv. 2013, 3 (39), 18016.

(16) Marnellos, G. Ammonia Synthesis at Atmospheric Pressure. Science (80). 1998, 282 (5386), 98-100.

(17) Tsuneto, A.; Kudo, A.; Sakata, T. Lithium-Mediated Electrochemical Reduction of High Pressure $\mathrm{N}_{2}$ to $\mathrm{NH}_{3}$. J. Electroanal. Chem. 1994, 367 (1-2), 183-188.

(18) Pappenfus, T. M.; Lee, K.; Thoma, L. M.; Dukart, C. R. Wind to Ammonia: Electrochemical Processes in Room Temperature Ionic Liquids. ECS Trans. 2009, 16 (49), 89-93.

(19) Murakami, T.; Nishikiori, T.; Nohira, T.; Ito, Y. Electrolytic Synthesis of Ammonia in Molten Salts under Atmospheric Pressure. J. Am. Chem. Soc. 2003, 125 (2), 334-335.

(20) Kawamura, F.; Taniguchi, T. Synthesis of Ammonia Using Sodium Melt. Sci. Rep. 2017, $7(1), 7-10$.

(21) Abghoui, Y.; Garden, A. L.; Howalt, J. G.; Vegge, T.; Skúlason, E. Electroreduction of $\mathrm{N}_{2}$ to Ammonia at Ambient Conditions on Mononitrides of $\mathrm{Zr}, \mathrm{Nb}, \mathrm{Cr}$, and V: A DFT Guide for Experiments. ACS Catal. 2016, 6 (2), 635-646.

(22) Köleli, F.; Kayan, D. B. Low Overpotential Reduction of Dinitrogen to Ammonia in 
Aqueous Media. J. Electroanal. Chem. 2010, 638 (1), 119-122.

(23) Chatt, J.; Pearman, A. J.; Richards, R. L. The Reduction of Mono-Coordinated Molecular Nitrogen to Ammonia in a Protic Environment. Nature 1975, 253 (5486), 39-40.

(24) Schrock, R. R. Catalytic Reduction of Dinitrogen to Ammonia by Molybdenum: Theory versus Experiment. Angew. Chemie - Int. Ed. 2008, 47 (30), 5512-5522.

(25) Song, Y.; Johnson, D.; Peng, R.; Hensley, D. K.; Bonnesen, P. V.; Liang, L.; Huang, J.; Yang, F.; Zhang, F.; Qiao, R.; et al. A Physical Catalyst for the Electrolysis of Nitrogen to Ammonia. Sci. Adv. 2018, 4 (4), 1-9.

(26) Strmcnik, D.; van der Vliet, D. F.; Chang, K.-C.; Komanicky, V.; Kodama, K.; You, H.; Stamenkovic, V. R.; Marković, N. M. Effects of $\mathrm{Li}^{+}, \mathrm{K}^{+}$, and $\mathrm{Ba}^{2+}$ Cations on the ORR at Model and High Surface Area Pt and Au Surfaces in Alkaline Solutions. J. Phys. Chem. Lett. 2011, 2 (21), 2733-2736.

Bhugun, I.; Lexa, D.; Savéant, J. M. Catalysis of the Electrochemical Reduction of Carbon Dioxide by Iron(0) Porphyrins. Synergistic Effect of Lewis Acid Cations. J. Phys. Chem. 1996, 100 (51), 19981-19985.

(28) Xue, S.; Garlyyev, B.; Watzele, S.; Liang, Y.; Fichtner, J.; Pohl, M. D.; Bandarenka, A. S. Influence of Alkali Metal Cations on the Hydrogen Evolution Reaction Activity of Pt, Ir, $\mathrm{Au}$, and Ag Electrodes in Alkaline Electrolytes. ChemElectroChem 2018, 4 (111), 1-5.

(29) Singh, M. R.; Kwon, Y.; Lum, Y.; Ager, J. W.; Bell, A. T. Hydrolysis of Electrolyte Cations Enhances the Electrochemical Reduction of $\mathrm{CO}_{2}$ over $\mathrm{Ag}$ and $\mathrm{Cu}$. J. Am. Chem. Soc. 2016, 138 (39), 13006-13012.

(30) Subbaraman, R.; Tripkovic, D.; Strmcnik, D.; Chang, K. C.; Uchimura, M.; Paulikas, a P.; Stamenkovic, V.; Markovic, N. M. Enhancing Hydrogen Evolution Activity in Water Splitting by Tailoring $\mathrm{Li}^{+}-\mathrm{Ni}(\mathrm{OH})_{2}-\mathrm{Pt}$ Interfaces. Science (80). 2011, 334 (December), 1256-1260.

(31) McEnaney, J. M.; Singh, A. R.; Schwalbe, J. A.; Kibsgaard, J.; Lin, J. C.; Cargnello, M.; Jaramillo, T. F.; Nørskov, J. K. Ammonia Synthesis from $\mathrm{N}_{2}$ and $\mathrm{H}_{2} \mathrm{O}$ Using a Lithium 
Cycling Electrification Strategy at Atmospheric Pressure. Energy Environ. Sci. 2017, 10 (7), 1621-1630.

(32) Guha, A.; Narayanaru, S.; Narayanan, T. N. Tuning the Hydrogen Evolution Reaction on Metals by Lithium Salt. ACS Appl. Energy Mater. 2018, 1, 7116-7122.

(33) Suo, L.; Borodin, O.; Gao, T.; Olguin, M.; Ho, J.; Fan, X.; Luo, C.; Wang, C.; Xu, K. "Water-in-Salt" Electrolyte Enables High-Voltage Aqueous Lithium-Ion Chemistries. Science (80 ). 2015, 350 (6263), 938-943.

(34) Zhang, X.; Kong, R.-M.; Du, H.; Xia, L.; Qu, F. Highly Efficient Electrochemical Ammonia Synthesis via Nitrogen Reduction Reactions on a VN Nanowire Array under Ambient Conditions. Chem. Commun. 2018, 54 (42), 5323-5325.

(35) Skúlason, E.; Bligaard, T.; Gudmundsdóttir, S.; Studt, F.; Rossmeisl, J.; Abild-Pedersen, F.; Vegge, T.; Jónsson, H.; Nørskov, J. K. A Theoretical Evaluation of Possible Transition Metal Electro-Catalysts for $\mathrm{N}_{2}$ Reduction. Phys. Chem. Chem. Phys. 2012, 14 (3), 12351245.

(36) Trasatti, S. Work Function, Electronegativity, and Electrochemical Behaviour of Metals. III. Electrolytic Hydrogen Evolution in Acid Solutions. J. Electroanal. Chem. 1972, 39 (1), 163-184.

(37) Suryanto, B. H. R.; Kang, C. S. M.; Wang, D.; Xiao, C.; Zhou, F.; Azofra, L. M.; Cavallo, L.; Zhang, X.; Macfarlane, D. R. Rational Electrode-Electrolyte Design for Efficient Ammonia Electrosynthesis under Ambient Conditions. ACS Energy Lett. 2018, 3 (6), $1219-1224$.

(38) Yu, J.; Li, C.; Li, B.; Zhu, X.; Zhang, R.; Ji, L.; Tang, D.; Asiri, A. M.; Sun, X.; Li, Q.; et al. A Perovskite $\mathrm{La}_{2} \mathrm{Ti}_{2} \mathrm{O}_{7}$ Nanosheet as an Efficient Electrocatalyst for Artificial $\mathrm{N}_{2}$ Fixation to $\mathrm{NH}_{3}$ in Acidic Media. ChemComm 2019, No. 70, 28-31.

(39) Zhu, X.; Liu, Z.; Liu, Q.; Luo, Y.; Shi, X.; Asiri, A. M.; Wu, Y.; Sun, X. Efficient and Durable $\mathrm{N}_{2}$ Reduction Electrocatalysis under Ambient Conditions : $\beta$-FeOOH Nanorods as a Non-Noble Metal Catalyst. ChemComm 2018, 54 (110), 11332-11335. 
(40) Zhao, J.; Wang, B.; Zhou, Q.; Wang, H.; Li, X.; Chen, H.; Wei, Q.; Wu, D.; Luo, Y.; You, J.; Gong, F. F.; Sun, X. Efficient Electrohydrogenation of $\mathrm{N}_{2}$ to $\mathrm{NH}_{3}$ by Oxidized Carbon Nanotubes under Ambient Conditions. ChemComm 2019, 55 (002), 4997-5000.

(41) Turcheniuk, K.; Bondarev, D.; Singhal, V.; Yushin, G. Ten Years Left to Redesign Lithium-Ion Batteries. Nature 2018, 559 (7715), 467-470.

(42) Morales-Guio, C. G.; Stern, L.-A.; Hu, X. Nanostructured Hydrotreating Catalysts for Electrochemical Hydrogen Evolution. Chem. Soc. Rev. 2014, 43 (18), 6555.

(43) Gao, M. Y.; Yang, C.; Zhang, Q. B.; Yu, Y. W.; Hua, Y. X.; Li, Y.; Dong, P. Electrochemical Fabrication of Porous Ni-Cu Alloy Nanosheets with High Catalytic Activity for Hydrogen Evolution. Electrochim. Acta 2016, 215, 609-616.

(44) Crosby, N. T. Determination of Ammonia by the Nessler Method in Waters Containing Hydrazine. Analyst 1968, 93 (1107), 406-408.

(45) Bolleter, W. T.; Bushman, C. J.; Tidwell, P. W. Spectrophotometric Determination of Ammonia as Indophenol. Anal. Chem. 1961, 33 (4), 592-594.

(46) Geng, Z.; Liu, Y.; Kong, X.; Li, P.; Li, K.; Liu, Z.; Du, J. Achieving a Record-High Yield

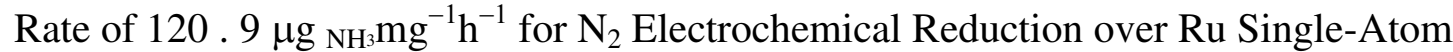
Catalysts. Adv. Mater. 2018, 1803498, 2-7.

(47) Watt, G. W.; Chrisp, J. D. A Spectrophotometric Method for the Determination of Hydrazine. Anal. Chem. 1952, 24 (12), 2006-2008.

(48) Developments, R.; Catalysts, N. R.; Issue, V. Recent Developments in Nitrogen Reduction. ACS Energy Lett. 2019, 4 (1), 163-166.

(49) Zhao, J.; Tran, P. D.; Chen, Y.; Loo, J. S. C.; Barber, J.; Xu, Z. J. Achieving High Electrocatalytic Efficiency on Copper: A Low-Cost Alternative to Platinum for Hydrogen Generation in Water. ACS Catal. 2015, 5 (7), 4115-4120.

(50) Shipman, M. A.; Symes, M. D. Recent Progress towards the Electrosynthesis of Ammonia from Sustainable Resources. Catal. Today 2017, 286, 57-68. 
(51) Garlyyev, B.; Xue, S.; Watzele, S.; Scieszka, D.; Bandarenka, A. S. Influence of the Nature of the Alkali Metal Cations on the Electrical Double-Layer Capacitance of Model Pt(111) and Au(111) Electrodes. J. Phys. Chem. Lett. 2018, 9 (8), 1927-1930.

(52) Jasra, R. V; Choudary, N. V; Bhat, S. G. T. Separation of Gases by Pressure Swin. Sep. Sci. Technol. 1991, 26 (7), 885-930.

(53) Choudary, V. N.; Jasra, R. V.; Bhat, T. S. G. Adsorption of a Nitrogen-Oxygen Mixture in $\mathrm{NaCaA}$ Zeolites by Elution Chromatography. Ind. Eng. Chem. Res. 1993, 32 (3), 548-552.

(54) Papai, I.; Goursot, A.; Fajula, F.; Plee, D.; Weber, J. Modeling of $\mathrm{N}_{2}$ and $\mathrm{O}_{2}$ Adsorption in Zeolites. J. Phys. Chem. 1995, 99 (34), 12925-12932.

\section{ToC}

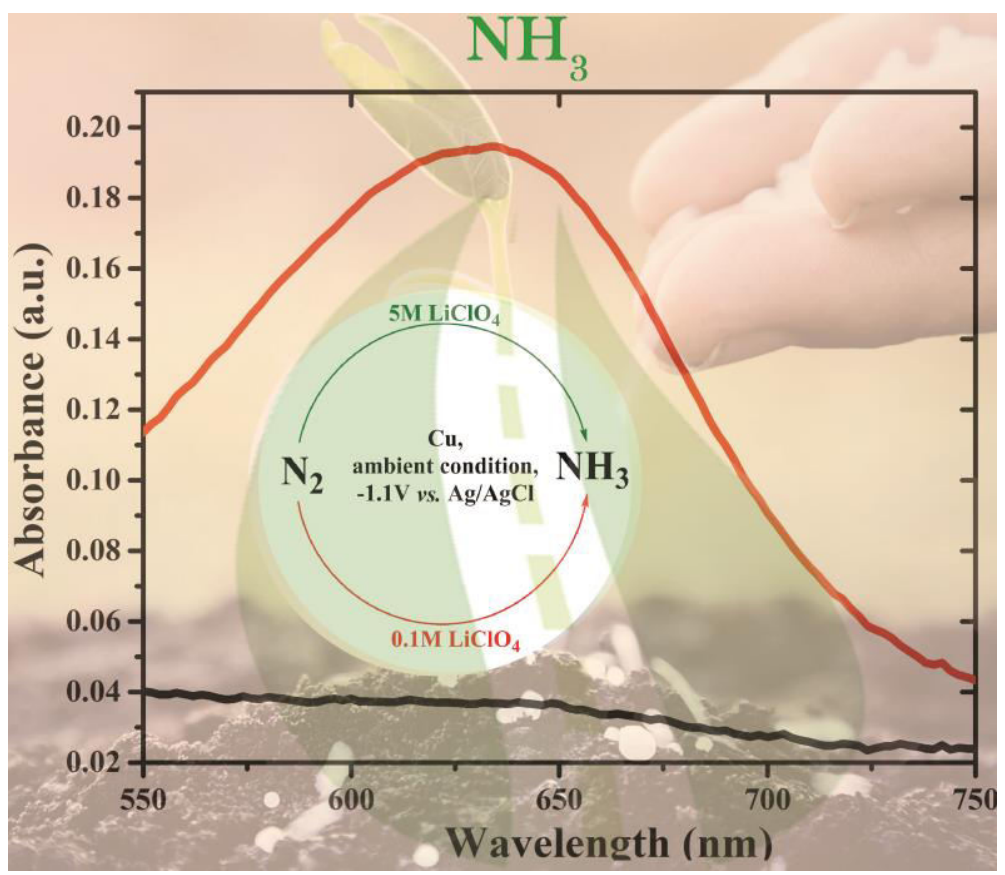




\title{
Supporting Information
}

\section{Mechanistic Insight into High Yield Electrochemical Nitrogen Reduction to Ammonia using Lithium Ions}

\author{
Anku Guha, Sreekanth Narayanaru, Nisheal M. Kaley, D. Krishna Rao, Jagannath Mondal, and \\ Tharangattu N. Narayanan*
}

Tata Institute of Fundamental Research - Hyderabad, Sy. No. 36/P, Gopanapally Village, Serilingampally Mandal, Hyderabad - 500107, India.

(Corresponding author: tnn@tifrh.res.in or tn_narayanan@yahoo.com)

\section{Materials:}

Lithium perchlorate $\left(\mathrm{LiClO}_{4}\right)$, Sodium perchlorate $\left(\mathrm{NaClO}_{4}\right)$, alumina powder $(50 \mu \mathrm{M}$ mesh size), salicylic acid, trisodium citrate, sodium hydroxide, sodium hypochlorite ( $\mathrm{NaClO})$, sodium nitroprusside, ethanol, N, N- dimethyl benzaldehyde, hydrochloric acid, ammonium chloride (both ${ }^{14} \mathrm{NH}_{4} \mathrm{Cl},{ }^{15} \mathrm{NH}_{4} \mathrm{Cl}$ ), hydrazine monohydrate, isopropanol, deuterium oxide $\left(\mathrm{D}_{2} \mathrm{O}\right)$ are used as received from Sigma-Aldrich without further purification. De-ionized water (Millipore, 18.2 $\mathrm{M} \Omega \cdot \mathrm{cm}$ ) is used as the solvent, Nitrogen (both ${ }^{14} \mathrm{~N}_{2}$ and ${ }^{15} \mathrm{~N}_{2}$ ) gas (99.99\%), Argon (Ar) gas $(99.99 \%)$ etc are used as received. Copper $(\mathrm{Cu})$ and Gold $(\mathrm{Au})$ electrodes are polished using alumina powder and then sonicated for $30 \mathrm{mins}$ in isopropanol and in DI water respectively before use. All chemicals are weighed as required and dissolved in DI water and $\mathrm{N}_{2}$ gas is purged for $30 \mathrm{~min}$ before electrolysis. Two compartment H-cell is used for bulk electrolysis separated by Nafion 117 membrane which is bought from Du Pont and pretreated as described and stored in DI water for further use. 


\section{Electrochemical Cell Set up:}

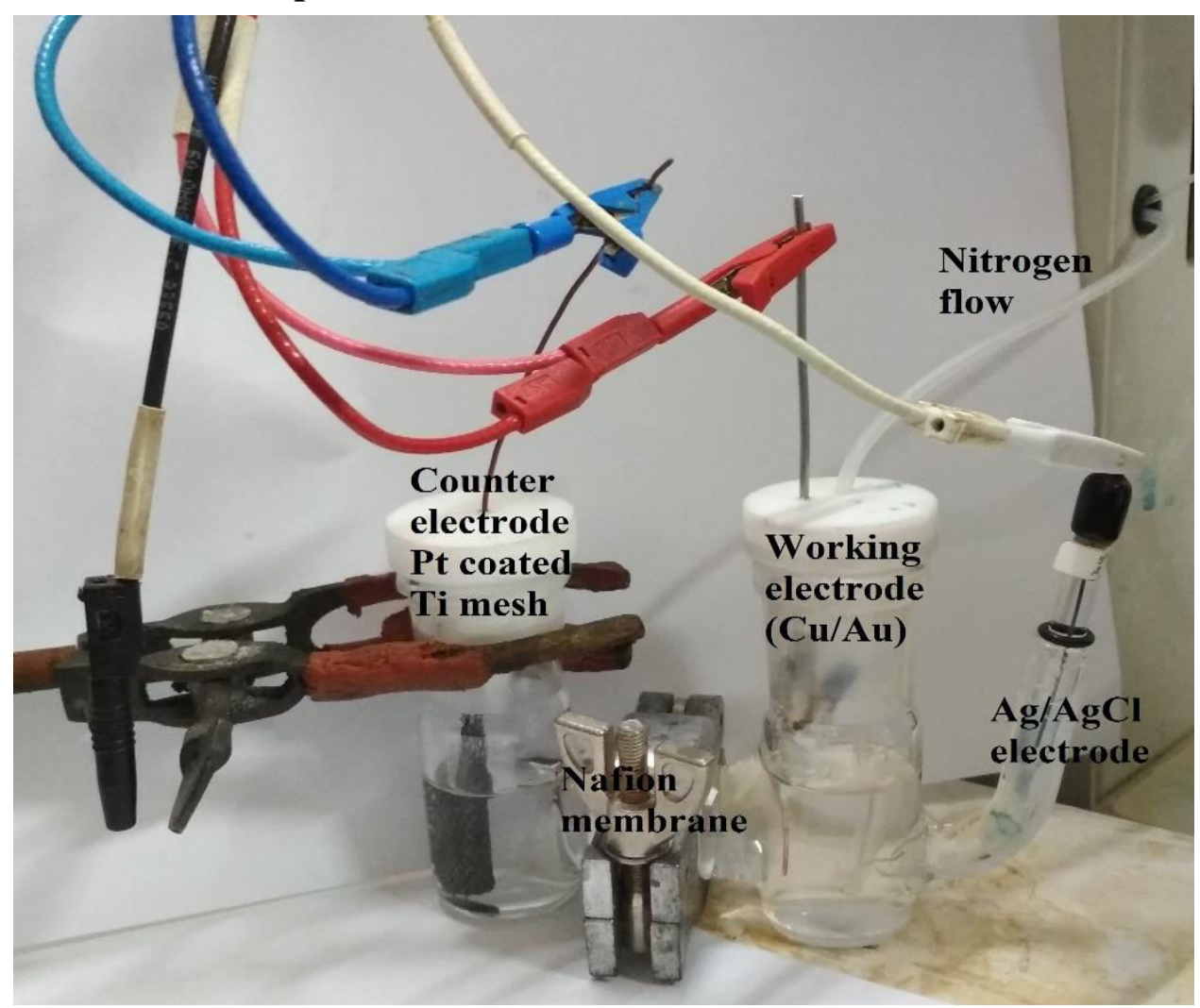

Figure S1: Photograph of the electrochemical cell set up.

A two compartments H-cell is used for the electrochemical reduction of nitrogen. Nafion 117 membrane is used as the separator between two compartments. The volume of the electrolyte in each compartment of the $\mathrm{H}$-cell is $19 \mathrm{~mL} .0 .1 \mathrm{M} \mathrm{LiClO}_{4}$ is used in the counter compartment of the $\mathrm{H}$-cell. The working electrode is kept parallel to the counter electrode to achieve uniform voltage. An identical cell setup is used for $5 \mathrm{M} \mathrm{NaClO}_{4}$ and in the counter electrode compartment $0.1 \mathrm{M} \mathrm{NaClO}$ is used instead of $0.1 \mathrm{M} \mathrm{LiClO}_{4}$. $\mathrm{N}_{2}$ or $\mathrm{Ar}$ is bubbled in the cathodic compartment throughout the reaction time. $\mathrm{Ag} / \mathrm{AgCl}$ is used as reference electrode. $\mathrm{Pt}$ coated $\mathrm{Ti}$ mesh is used as counter electrode. For LSV measurements three electrode single compartment cell with $\mathrm{Pt}$ (and graphite) as counter electrode and $\mathrm{Ag} / \mathrm{AgCl}$ as reference electrode are used. 


\section{Analysis of $\mathrm{NH}_{3}$ by indophenol test:}

Produced ammonia from $\mathrm{N}_{2}$ reduction is identified and quantified by slightly modified indophenol method ${ }^{1,2}$. Procedure of the indophenol method is as follows

1. After electrolysis $2 \mathrm{~mL}$ of the electrolyte is removed from the $\mathrm{H}$ - cell.

2. $2 \mathrm{~mL}$ of $1 \mathrm{M} \mathrm{NaOH}$ solution containing $5 \mathrm{wt} . \%$ salicylic acid and $5 \mathrm{wt} . \%$ trisodium citrate is added into previous solution.

3. Then $1 \mathrm{~mL}$ of $0.05 \mathrm{M}$ sodium hypochloritefollowed by $0.1 \mathrm{~mL}$ of 1 wt. $\%$ sodium nitroferricyanide is added.

The solution is kept for $1 \mathrm{~h}$ for color generation and then the absorption spectrum is measured using a UV-Vis spectrophotometer. The maximum absorbance is detected at $632 \mathrm{~nm}$ and concentration of the ammonia is measured from the calibration curve. The concentrationabsorbance curves are calibrated by using standard ammonium chloride solution containing $5 \mathrm{M}$ $\mathrm{LiClO}_{4}$ solution which is electrolyte.

\section{Determination of hydrazine hydrate:}

To detect and quantify hydrazine formed in the reaction electrolyte, the method of Watt and

Chrisp $^{3}$ is used. A mixture of para-(dimethylamino) benzaldehyde (5.99 g), $\mathrm{HCl}$ (concentrated, $30 \mathrm{~mL})$ and ethanol $(300 \mathrm{~mL})$ is used as a color reagent. Procedure of this method as follows

1. After electrolysis $2 \mathrm{~mL}$ of the electrolyte is removed from the $\mathrm{H}$ - cell.

2. $2 \mathrm{~mL}$ of color reagent which is prepared by above mentioned procedure, is added into the previous solution.

The solution is kept for 10 min and then the absorption spectrum is measured using a UV-Vis spectro-photometer. No maximum absorbance is detected at $460 \mathrm{~nm}$.

\section{Calculation of faradaic efficiency:}


The faradaic efficiency is calculated by using following formula ${ }^{4}$ :

$\% \mathrm{FE}=\frac{3 * X * 10^{-6} * F * V}{I * t} * 100$ where,

$X=$ Concentration of produced $\mathrm{NH}_{3}$ in mole/L.

$\mathrm{V}=$ Volume of the electrolyte in L.

$\mathrm{F}=$ Faraday Constant.

$I=$ The current measured by the potentiostat for applying a potential in ampere.

$\mathrm{t}=$ Total time for the experiment in second.

\section{Rate of formation of ammonia:}

Rate $^{5}$ of formation of ammonia $=\frac{X * V}{t * A}$ where,

$\mathrm{X}=$ Concentration ammonia in mole/L.

$\mathrm{V}=$ Volume of electrolyte.

$\mathrm{T}=$ Time for chronoamperometry, here $1800 \mathrm{~s}$.

$\mathrm{A}=$ Surface area of the electrode, here $2.55 \mathrm{~cm}^{2}$.

\section{Electrochemical measurements:}

All electrochemical measurements are done by a two channels bio-logic SP-300 work station using $\mathrm{Ag} / \mathrm{AgCl}$ as reference electrode and $\mathrm{Pt}$ coated titanium mesh or $\mathrm{Pt}$ as counter electrode. A single compartment cell and a two compartments H-cell separated by Nafion 117 membrane are used to measure the LSVs and chronoamperometries respectively. Before performing the LSVs or chronoamperometries, the electrolyte solutions are saturated by Argon (Ar) or by nitrogen $\left(\mathrm{N}_{2}\right)$ for 30 min.Copper and gold electrode (geometrical surface area $2.55 \mathrm{~cm}^{2}$ ) are mechanically polished using alumina powder $(50 \mu \mathrm{m}$ mesh size). Then the electrodes are sonicated in isopropanol and DI water respectively for $30 \mathrm{mins}$. The electrodes are cycled for 10 times to measure the LSVs from 0 to $-1.5 \mathrm{~V} v s$. $\mathrm{Ag} / \mathrm{AgCl}$ counter at a scan rate $200 \mathrm{mV} / \mathrm{s}$.

\section{UV-Vis spectra measurements:}

All UV-Vis spectra are measured using a Jasco V-670 UV-Vis spectrophotometer with a scan rate $200 \mathrm{~nm} / \mathrm{min}$ from 750 to $550 \mathrm{~nm}$ range for ammonia detection and 600-440 $\mathrm{nm}$ for hydrazine detection. The data is measured with a data interval of $2 \mathrm{~nm}$. The spectra are taken 
after 60 mins for ammonia and after 10 mins for hydrazine. Path length of the quartz cell is 10 $\mathrm{cm}$.

\section{Nafion117 membrane pretreatment:}

Nafion 117 membrane is washed with DI water for several times. Then it is heated at $80^{\circ} \mathrm{C}$ for $1 \mathrm{~h}$ in $3 \% \mathrm{H}_{2} \mathrm{O}_{2}$ followed by another $2 \mathrm{~h}$ boiling at same temperature in DI water. Then it is again boiled in $0.5 \mathrm{M} \mathrm{H} 2 \mathrm{SO} 4$ at same temperature. This pretreated nafion 117 membrane is washed several times with DI water and stored in DI water at room temperature for further use.

\section{0. ${ }^{1} \mathrm{H}$ NMR:}

${ }^{1} \mathrm{H}$ NMR are measured by a $300 \mathrm{MHz}$ Bruker Nano bay spectrometer. All the NMR data are recorded at $25^{\circ} \mathrm{C}$ with a spectral width of $12 \mathrm{ppm}$ with 512 scans with water pre-saturation. The obtained signals are confirmed by comparing with the signal of $0.15 \mathrm{M}^{14} \mathrm{NH}_{4} \mathrm{Cl}$ in $5 \mathrm{M} \mathrm{LiClO}_{4}$ along with $1 \mathrm{M} \mathrm{HCl}$ and $10 \% \mathrm{D}_{2} \mathrm{O} .{ }^{1} \mathrm{H} \mathrm{NMR}$ samples are prepared by mixing of $5 \mathrm{M} \mathrm{LiClO} 4$ (saturated with ${ }^{14} \mathrm{~N}_{2}$ ) before and after electrolysis at $-1.1 \mathrm{~V} v s$. $\mathrm{Ag} / \mathrm{AgCl}$ for 30 mins along with $1 \mathrm{M} \mathrm{HCl}$ and $10 \% \mathrm{D}_{2} \mathrm{O}$.

\section{1. ${ }^{1} \mathrm{H}$ NMR for labeling experiment:}

Since ${ }^{15} \mathrm{~N}_{2}$ gas is expensive (Sigma Aldrich ${ }^{15} \mathrm{~N}_{2}$ 364584-250ML 28000/- (INR), figure S10A), the labeling experiment is conducted in a single compartment cell (air tightened cell which is initially saturated with argon followed by NRR as discussed in the following statements, figure S10B) after saturation with ${ }^{14} \mathrm{~N}_{2}$ and/or also using the mixture of ${ }^{14} \mathrm{~N}_{2}$ and ${ }^{15} \mathrm{~N}_{2}$ by purging the ${ }^{15} \mathrm{~N}_{2}$ directly to the electrolyte, and the electrolysis is performed up to 24 hour (h) at $-1.1 \mathrm{~V} v s$. $\mathrm{Ag} / \mathrm{AgCl}$ using $\mathrm{Cu}$ electrode. Details of the experiment are as follows: initially, $5 \mathrm{M} \mathrm{LiClO}_{4}$ is degassed by purging Ar for 30 minutes. After complete degassing using Ar, the electrolyte is saturated with ${ }^{14} \mathrm{~N}_{2}$ and sealed with septum as shown in the figure $\mathrm{S} 10 \mathrm{~B}$ to perform the electrolysis for 24 hour at $-1.1 \mathrm{~V}$ vs. $\mathrm{Ag} / \mathrm{AgCl}$ on $\mathrm{Cu}$. For the labeling experiment with ${ }^{15} \mathrm{~N}_{2}$,

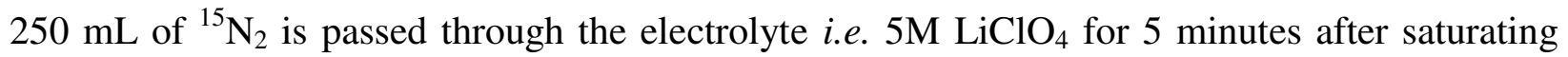
with ${ }^{14} \mathrm{~N}_{2}$ before making it air tight with septa. ${ }^{1} \mathrm{H} \mathrm{NMR}$ are measured by a $300 \mathrm{MHz}$ Bruker Nano bay spectrometer at $25^{\circ} \mathrm{C}$ with a spectral width of $12 \mathrm{ppm}$ with 6000 scans with water presaturation. The obtained NMR signals are confirmed by comparing with previous literature data, ${ }^{6}$ and also comparing with the signal obtained from the standard (known) samples of $0.15 \mathrm{M}$ ${ }^{14} \mathrm{NH}_{4} \mathrm{Cl}$ and ${ }^{15} \mathrm{NH}_{4} \mathrm{Cl}$ in $5 \mathrm{M} \mathrm{LiClO}$ along with $1 \mathrm{M} \mathrm{HCl}$ and $10 \% \mathrm{D}_{2} \mathrm{O}$. ${ }^{1} \mathrm{H} \mathrm{NMR}$ samples are prepared by mixing of $5 \mathrm{M} \mathrm{LiClO}_{4}$ (saturated with ${ }^{14} \mathrm{~N}_{2}$ or the mixture of ${ }^{14} \mathrm{~N}_{2}$ and ${ }^{15} \mathrm{~N}_{2}$ ) after electrolysis at $-1.1 \mathrm{~V}$ vs. $\mathrm{Ag} / \mathrm{AgCl}$ for 24 hour along with $1 \mathrm{M} \mathrm{HCl}$ and $10 \% \mathrm{D}_{2} \mathrm{O}$.

\section{Computational details:}


Density Functional Theory (DFT) based calculations are performed using the Spanish Initiative for Electronic Simulations of Thousands of Atoms- SIESTA 4.0 package. ${ }^{7}$ Pseudo-potentials for each element are generated using the ATOM program $^{8}$ in the norm-conserving TroullierMartins ${ }^{9}$ schemegeneralized gradient approximation revised Perdew-Burke-Ernzhenof (RPBE) [4] electron correlation functional. After convergence tests, the mesh cutoff is set to 343 Rydberg, a k-points mesh setup using a grid cutoff radius of 7 lattice constants for $\mathrm{Cu}$ and $\mathrm{Au}$ respectively, a Methfessel-Paxton ordering of degree 2, and at least $10 \AA$ of vacuum in Z-axis. A 3X2X2 lattice for $\mathrm{Cu}$ and $\mathrm{Au}$ face-centered surfaces are used as electrodes with lithium fluoride (LiF) occupying hollow sites and a single Nitrogen molecule in the bridge site. The system consisted of slab of 48 atoms in (001) plane distributed across four layers of which the bottom two are kept completely frozen during relaxations. Relaxations are done only in the Z-axis as the minor X-Y displacements contributed less significantly to final energy. Further simplicity during nitrogen reduction reaction (NRR) relaxation involved complete freezing of coordinates of the species $\mathrm{Cu}, \mathrm{Au}, \mathrm{Li}, \mathrm{F}$ and only $\mathrm{Z}$ axis displacements allowed for $\mathrm{N}$ molecule.

The adsorption of Nitrogen on the surface $\mathrm{S}$ is studied in the complete absence and presence of $\mathrm{Li}^{+}$. A maximum of $24 \mathrm{LiF}$ molecules could fit in the $3 \mathrm{X} 2$ cell hollow sites leaving the bridge and top sites vacant. The bridge sites being the more favorable is selected for NRR. To compute the adsorption energy the following equation is used:

$\Delta E=E\left(S+N_{2}\right)-E(S)-E\left(N_{2}\right)$, Where $\Delta E=$ adsorption energy of $N_{2}$ on $C u$ or Au surface, $S$.
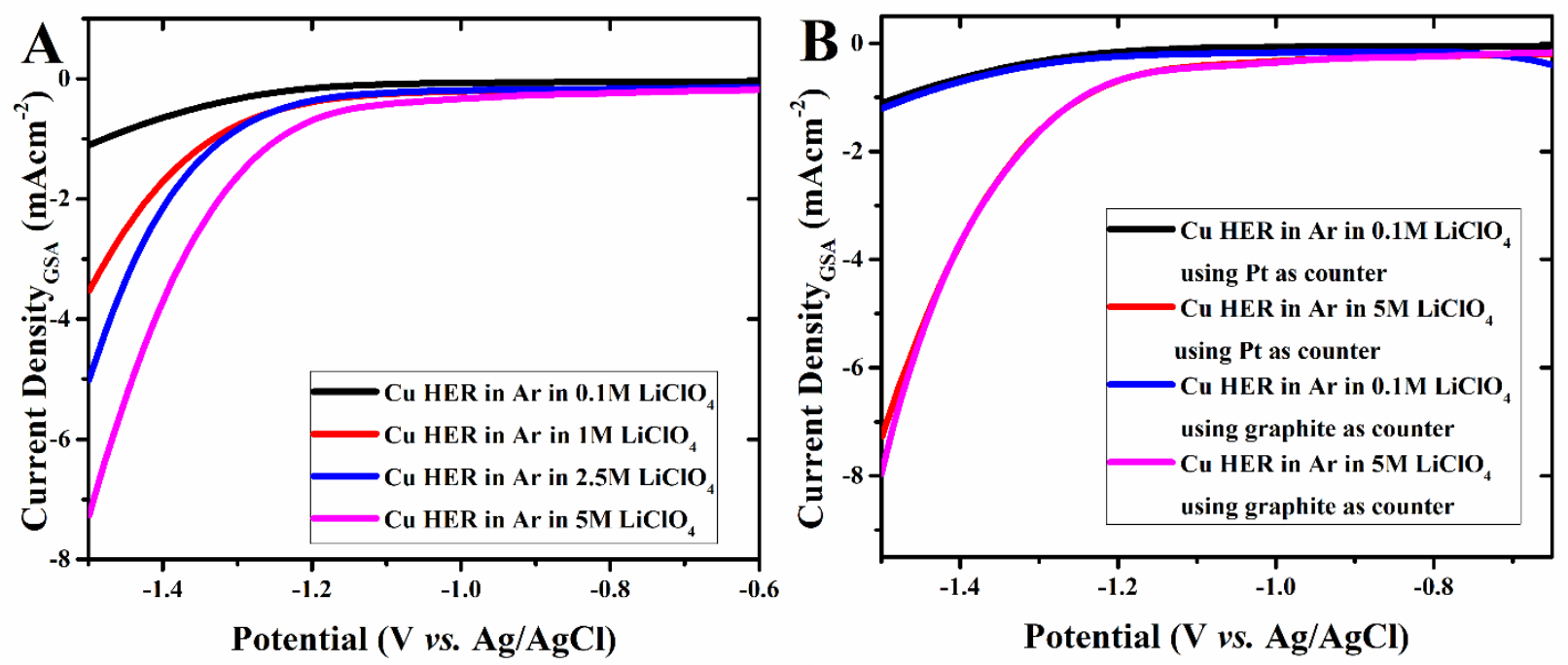

Figure S2: Cu HER in different concentration of $\mathrm{LiClO}_{4}$ in $\mathrm{Ar}$ : (A) using $\mathrm{Pt}$ as counter electrode and (B) Graphite rod as counter electrode at a scan rate $50 \mathrm{mV} / \mathrm{s}$. 


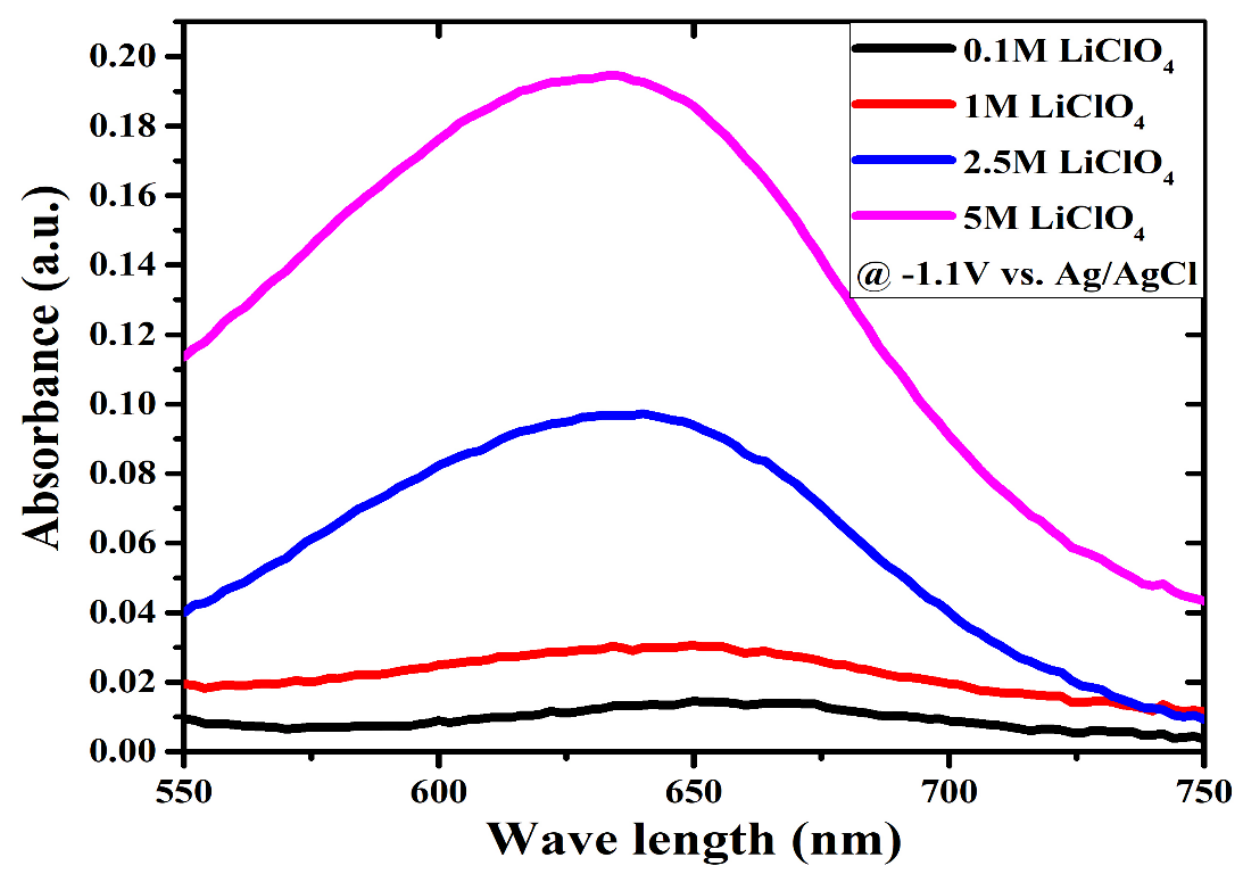

Figure S3: Absorbance vs. wavelength for $\mathrm{NH}_{3}$ for Copper electrode $(\mathrm{Cu})$ in different concentration of $\mathrm{LiClO}_{4}$ at $-1.1 \mathrm{~V} v s . \mathrm{Ag} / \mathrm{AgCl}$.
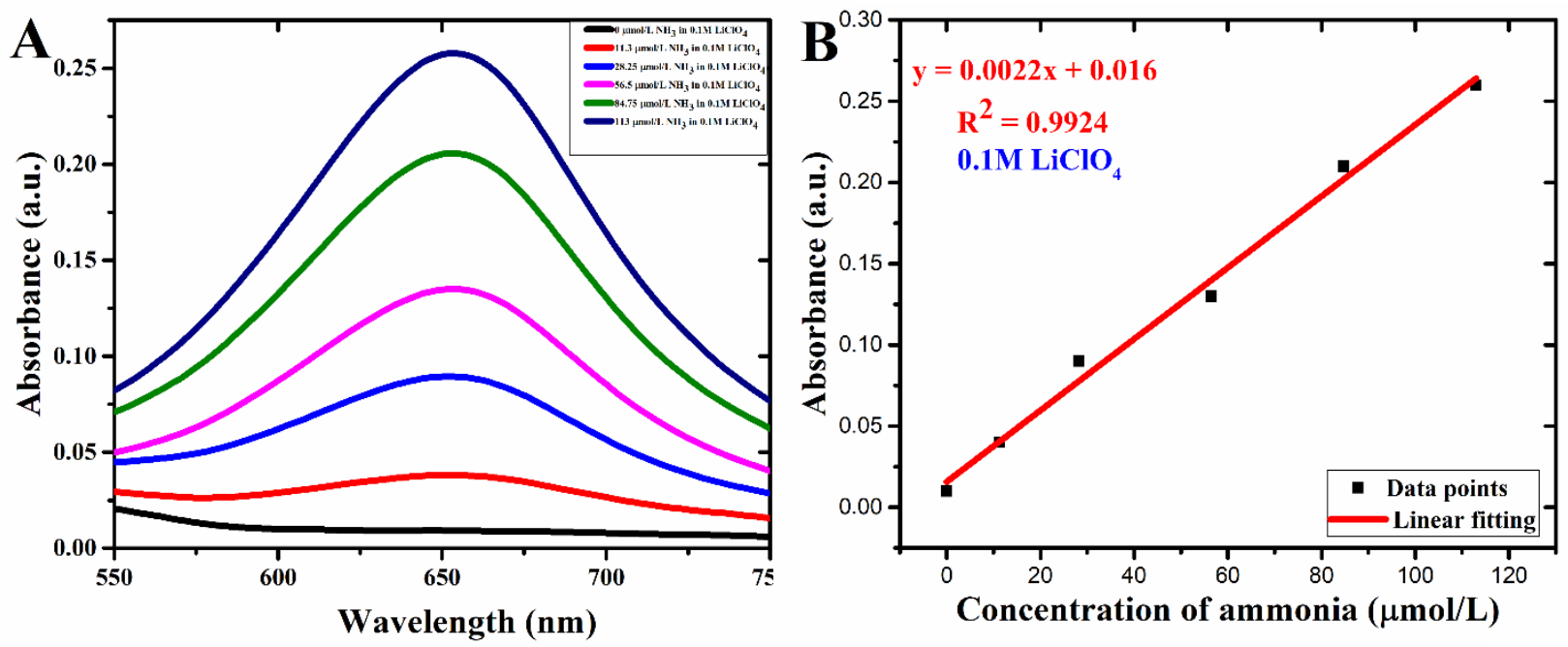

Figure S4: A) Absorbance vs. wavelength with different concentration of ammonium chloride in $0.1 \mathrm{M} \mathrm{LiClO}_{4}, \mathrm{~B}$ ) Calibration curve for produced ammonia (Absorbance $v s$. Concentration of ammonia) in $0.1 \mathrm{M} \mathrm{LiClO}_{4}$. 

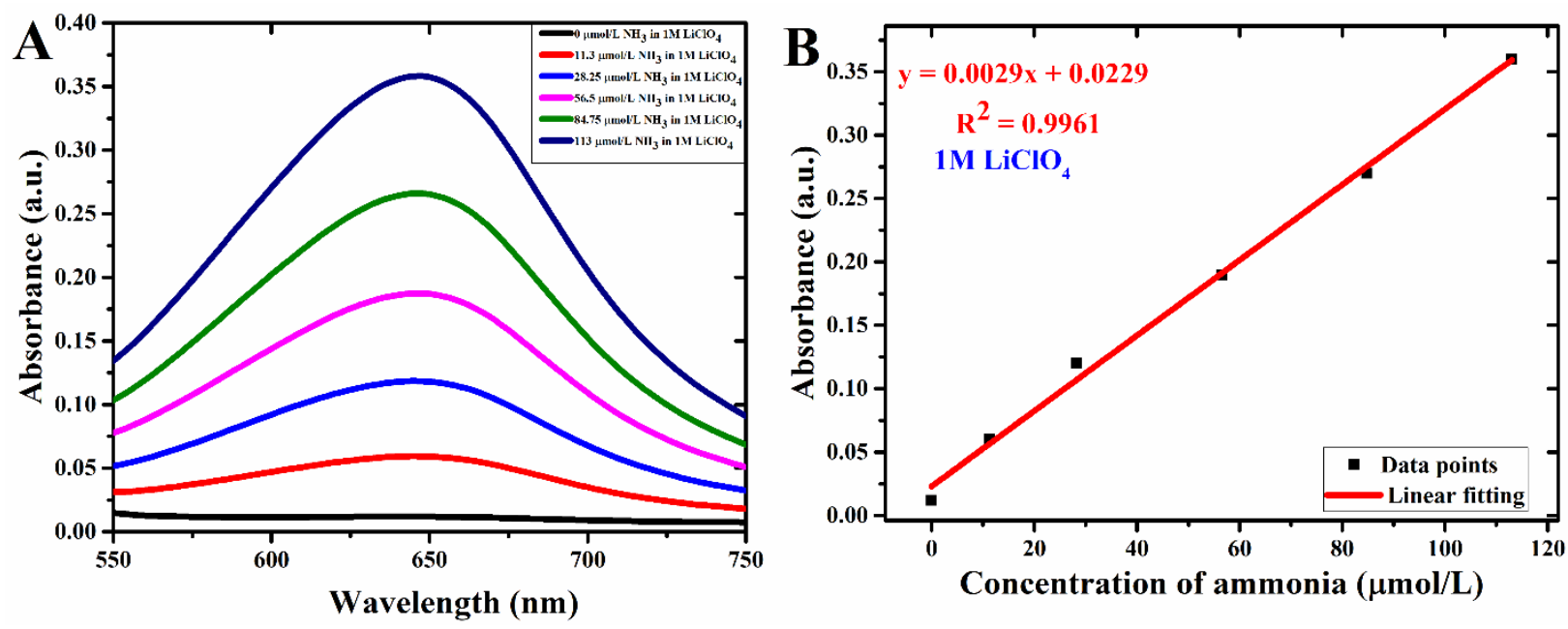

Figure S5: (A) Absorbance vs. wavelength with different concentration of ammonium chloride in $1 \mathrm{M} \mathrm{LiClO}_{4}$, (B) Calibration curve for produced ammonia (Absorbance vs. Concentration of ammonia) in $1 \mathrm{M} \mathrm{LiClO}_{4}$.
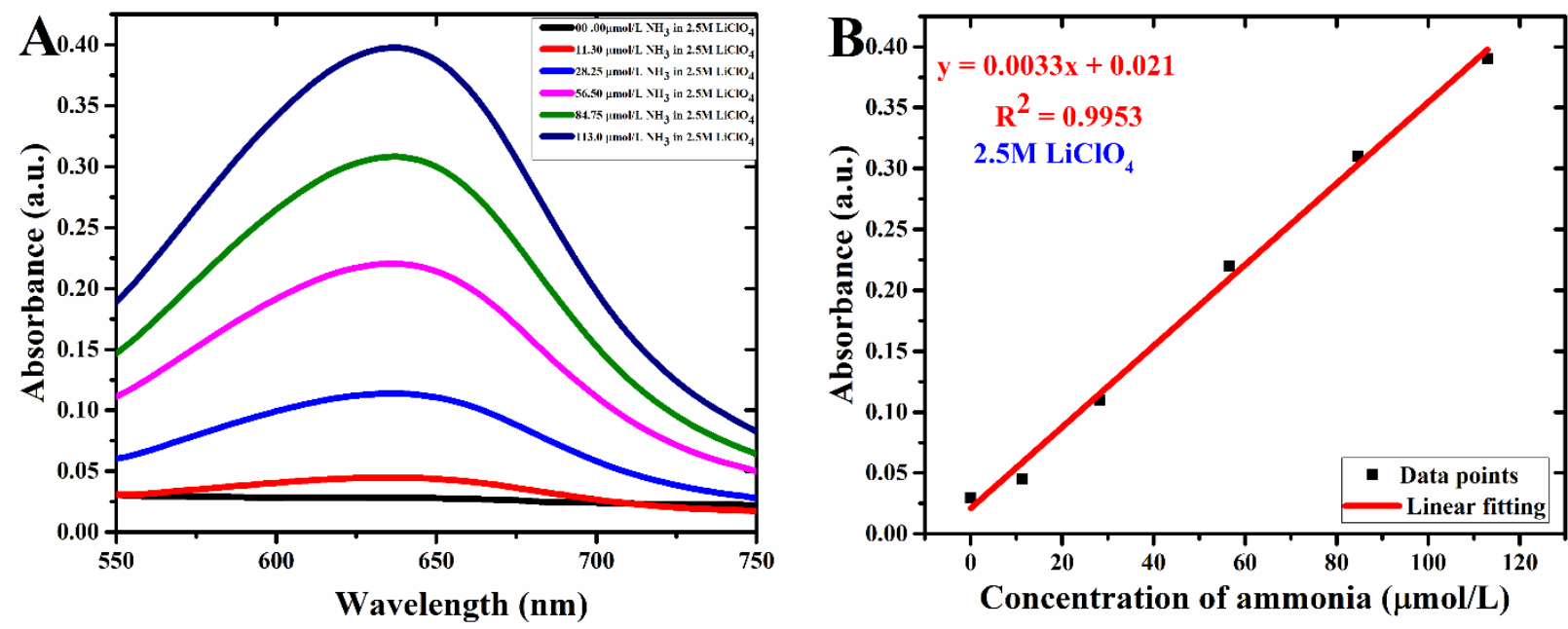

Figure S6: A) Absorbance vs. wavelength with different concentration of ammonium chloride in $2.5 \mathrm{M} \mathrm{LiClO}_{4}, \mathrm{~B}$ ) Calibration curve for produced ammonia (Absorbance vs. Concentration of ammonia) in $2.5 \mathrm{M} \mathrm{LiClO}_{4}$. 

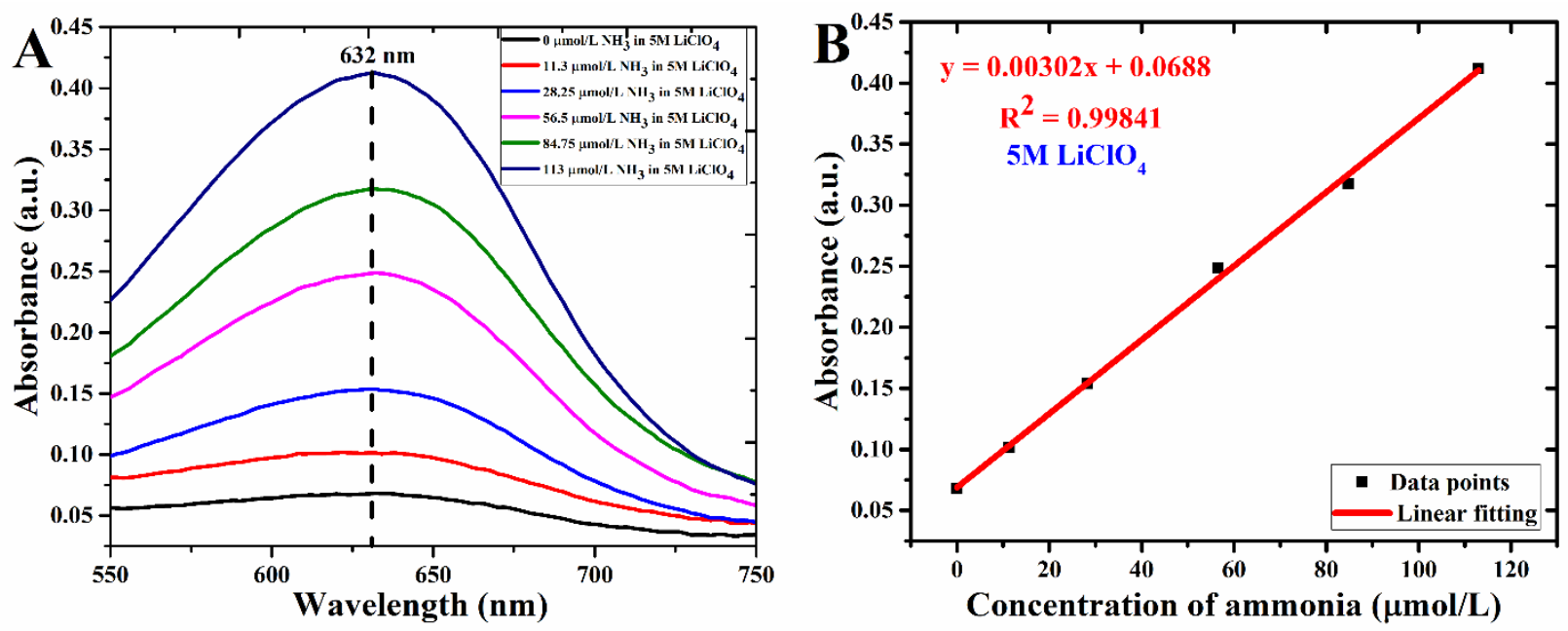

Figure S7: A) Absorbance vs. wavelength with different concentration of ammonium chloride in $5 \mathrm{M} \mathrm{LiClO}_{4}$, B) Calibration curve for produced ammonia (Absorbance vs. Concentration of ammonia) in $5 \mathrm{M} \mathrm{LiClO}_{4}$.
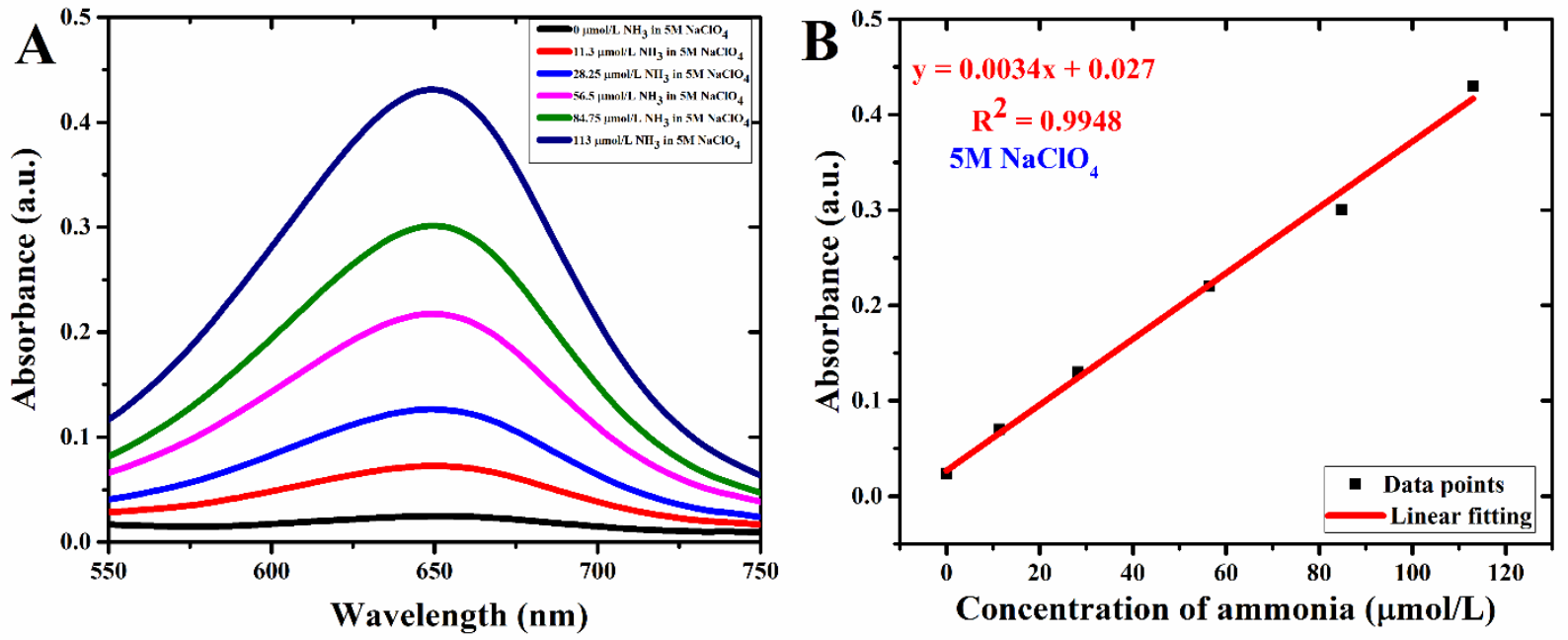

Figure S8: A) Absorbance vs. wavelength with different concentration of ammonium chloride in $5 \mathrm{M} \mathrm{NaClO}_{4}, \mathrm{~B}$ ) Calibration curve for produced ammonia (Absorbance vs. Concentration of ammonia) in $5 \mathrm{M} \mathrm{NaClO}_{4}$. 


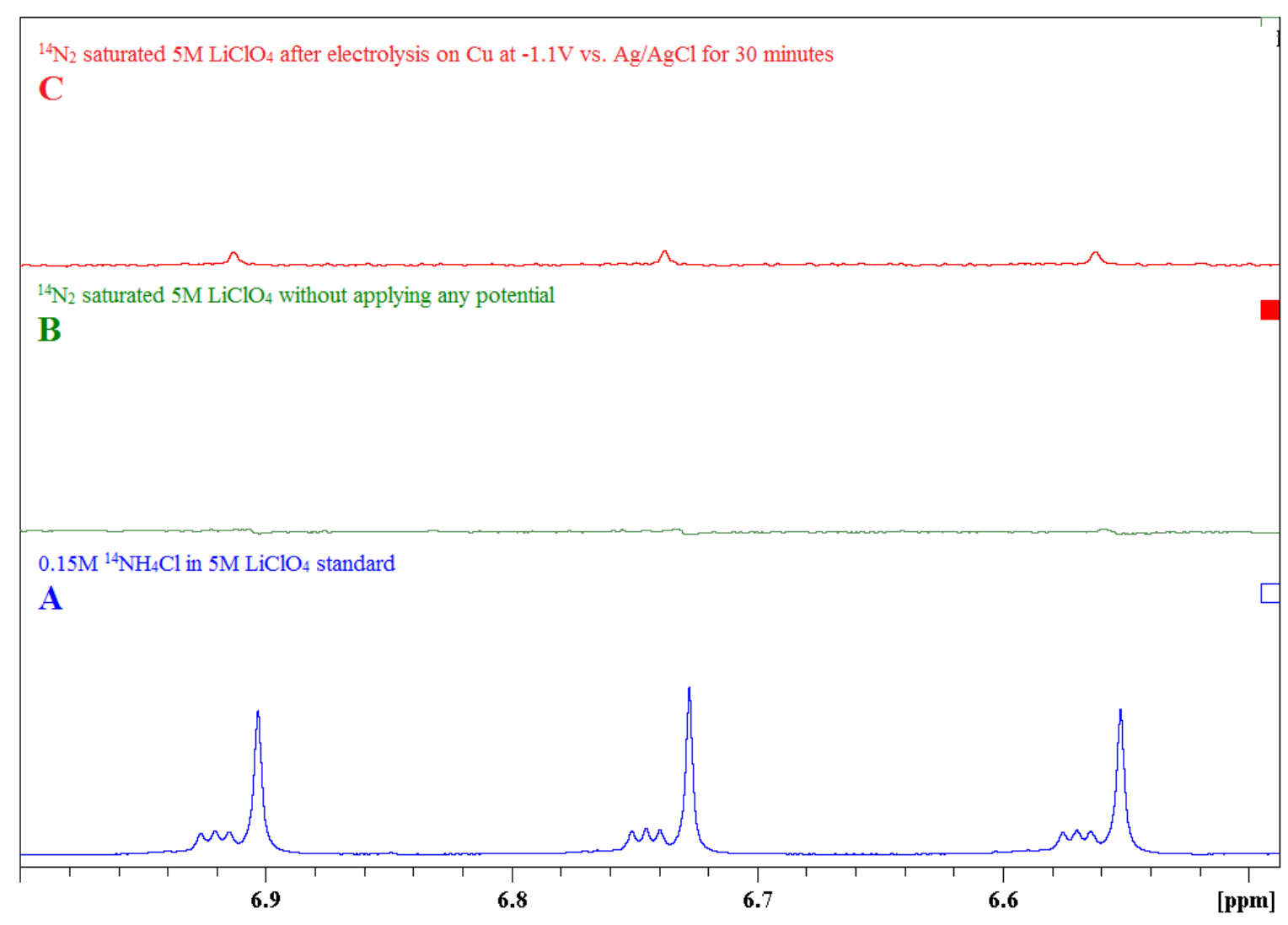

Figure S9: ${ }^{1} \mathrm{H}$ NMR spectra of: (A) $0.15 \mathrm{M}^{14} \mathrm{NH}_{4} \mathrm{Cl}$ in $5 \mathrm{M} \mathrm{LiClO}_{4}$, (B) ${ }^{14} \mathrm{~N}_{2}$ saturated $5 \mathrm{M}$ $\mathrm{LiClO}_{4}$ without applying any potential, and (C) saturated $5 \mathrm{M} \mathrm{LiClO}_{4}$ after electrolysis on $\mathrm{Cu}$ at $-1.1 \mathrm{~V} v s . \mathrm{Ag} / \mathrm{AgCl}$ for 30 minutes.
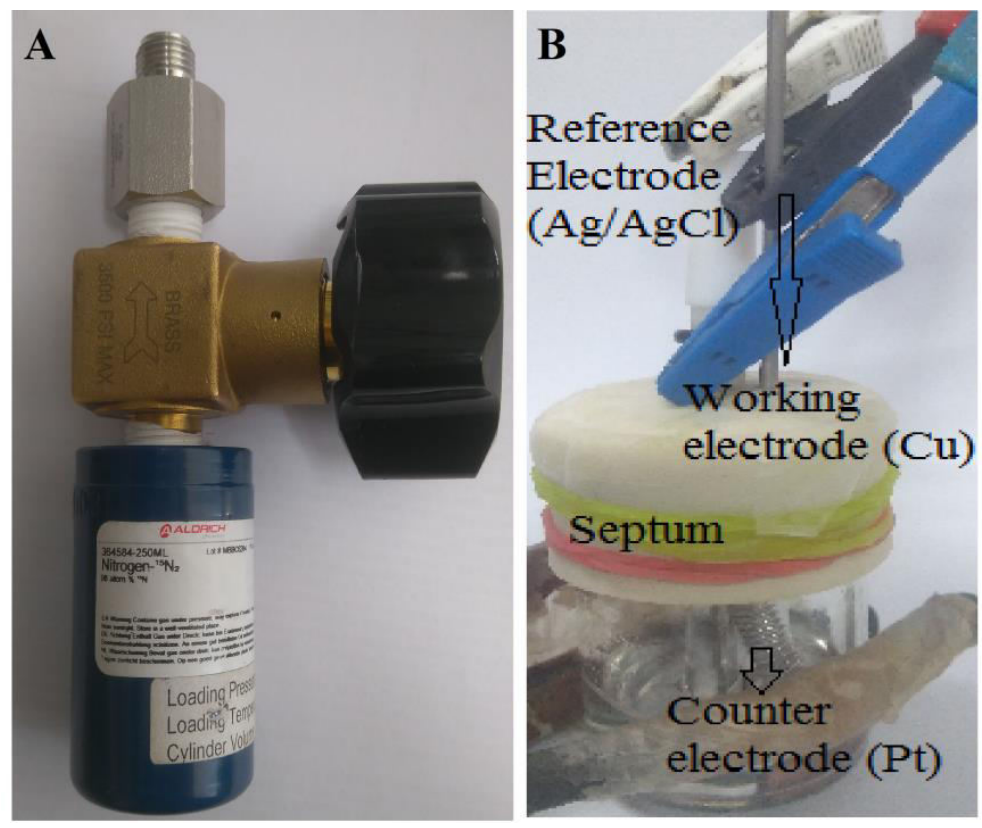

Figure S10: (A) $250 \mathrm{~mL}{ }^{15} \mathrm{~N}_{2}$ cylinder from Sigma Aldrich and, (B) electrochemical cell setup for labeling experiment. 


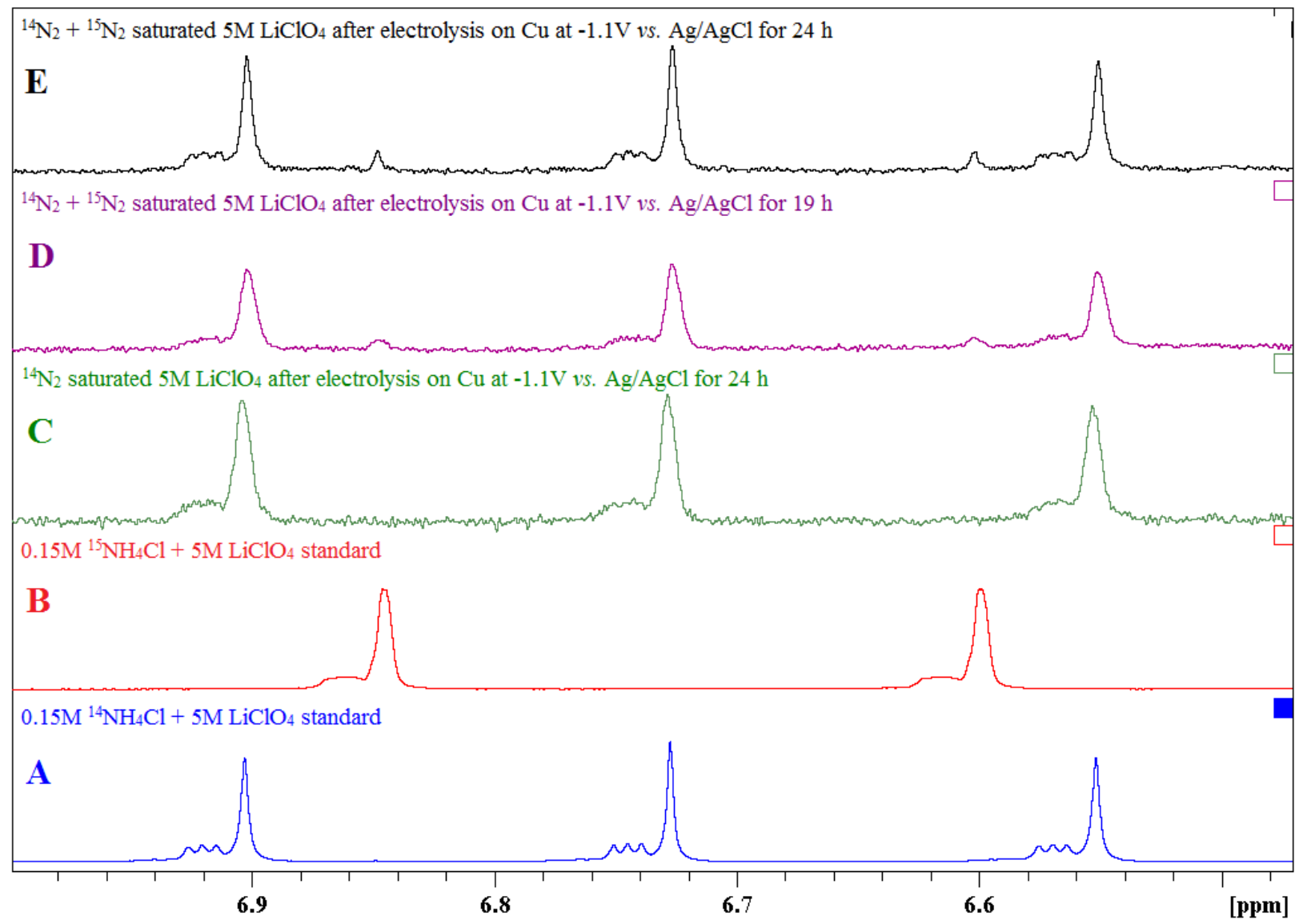

Figure S11: : ${ }^{1} \mathrm{H}$ NMR spectra of: (A) $0.15 \mathrm{M}^{14} \mathrm{NH}_{4} \mathrm{Cl}$ in $5 \mathrm{M} \mathrm{LiClO}_{4}$, (B) $0.15 \mathrm{M}^{15} \mathrm{NH}_{4} \mathrm{Cl}$ in $5 \mathrm{M} \mathrm{LiClO}_{4},(\mathrm{C}){ }^{14} \mathrm{~N}_{2}$ saturated $5 \mathrm{M} \mathrm{LiClO} 4$ after electrolysis on $\mathrm{Cu}$ at $-1.1 \mathrm{~V} v$ s. $\mathrm{Ag} / \mathrm{AgCl}$ for 24 h, (D) mixture of ${ }^{14} \mathrm{~N}_{2}$ and ${ }^{15} \mathrm{~N}_{2}$ saturated $5 \mathrm{M} \mathrm{LiClO}_{4}$ after electrolysis on $\mathrm{Cu}$ at $-1.1 \mathrm{~V}$ vs. $\mathrm{Ag} / \mathrm{AgCl}$ for $19 \mathrm{~h}$ and (E) ) mixture of ${ }^{14} \mathrm{~N}_{2}$ and ${ }^{15} \mathrm{~N}_{2}$ saturated $5 \mathrm{M} \mathrm{LiClO}_{4}$ after electrolysis on Cu at $-1.1 \mathrm{~V} v s$. $\mathrm{Ag} / \mathrm{AgCl}$ for $24 \mathrm{~h}$. 


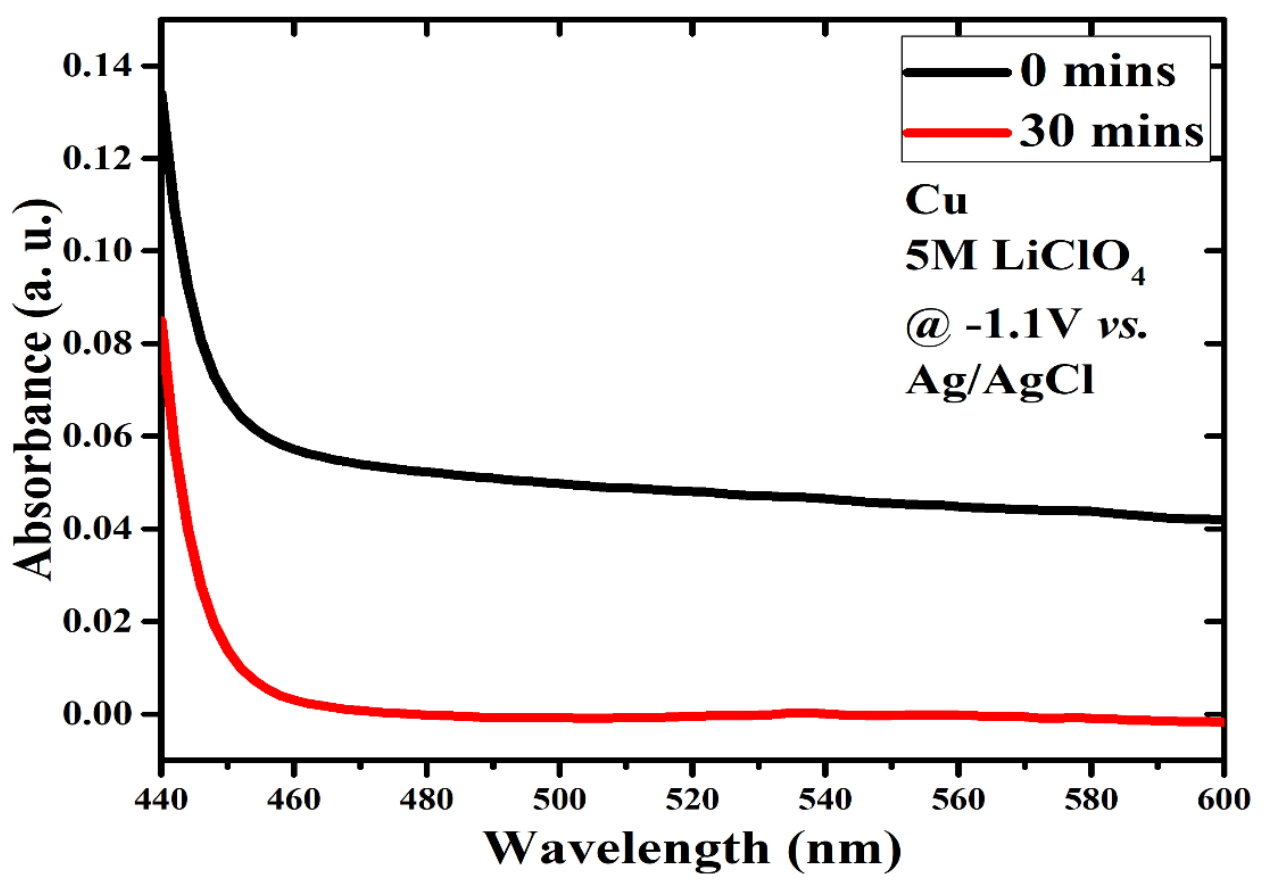

Figure S12: Absorbance vs. wavelength for Copper electrode $(\mathrm{Cu})$ for hydrazine in $5 \mathrm{M} \mathrm{LiClO}_{4}$ at $-1.1 \mathrm{~V} v s . \mathrm{Ag} / \mathrm{AgCl}$.

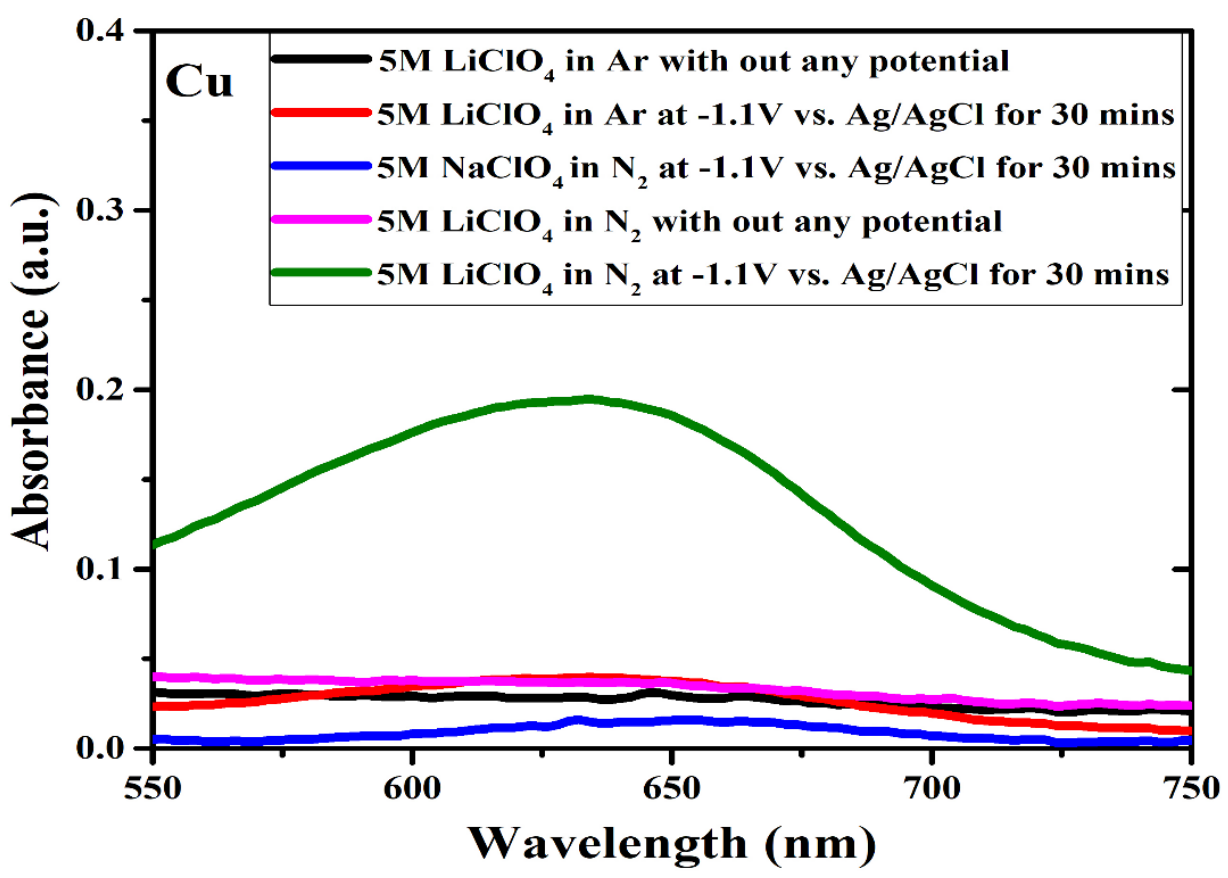

Figure S13: Absorbance vs. wavelength for $\mathrm{NH}_{3}$ for Copper electrode $(\mathrm{Cu})$ in $5 \mathrm{M} \mathrm{LiClO}_{4}$ at $-1.1 \mathrm{~V}$ vs. $\mathrm{Ag} / \mathrm{AgCl}$ in $\mathrm{Ar}$ (red), in $\mathrm{N}_{2}$ (green), without applying any potential in $\mathrm{N}_{2}$ (pink) and, in $5 \mathrm{M} \mathrm{NaClO}_{4}$ in $\mathrm{N}_{2}$ (blue). 


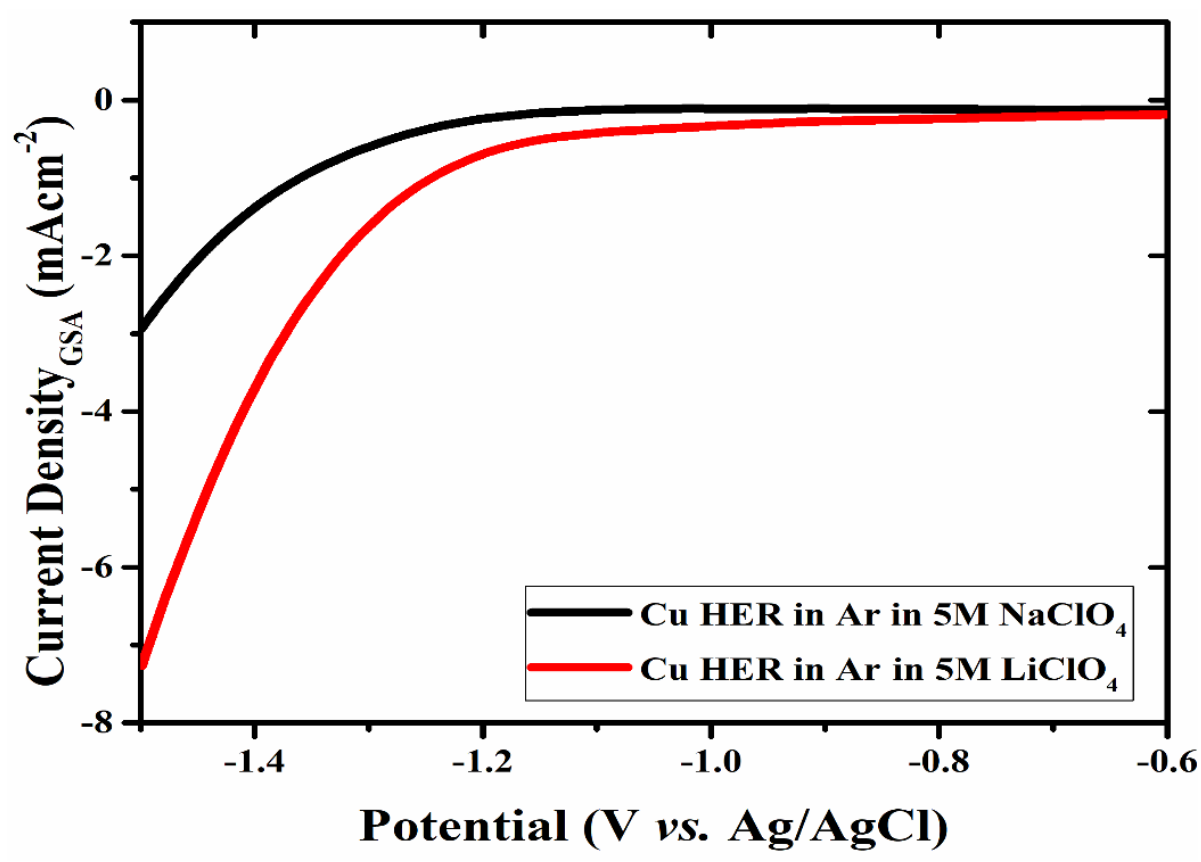

Figure S14: LSVs using Cu electrode at $50 \mathrm{mV} / \mathrm{s}$ scan rate in $5 \mathrm{MLiClO}_{4}$ (red)and in $5 \mathrm{M} \mathrm{NaClO}_{4}$ (black) in Ar atmosphere.

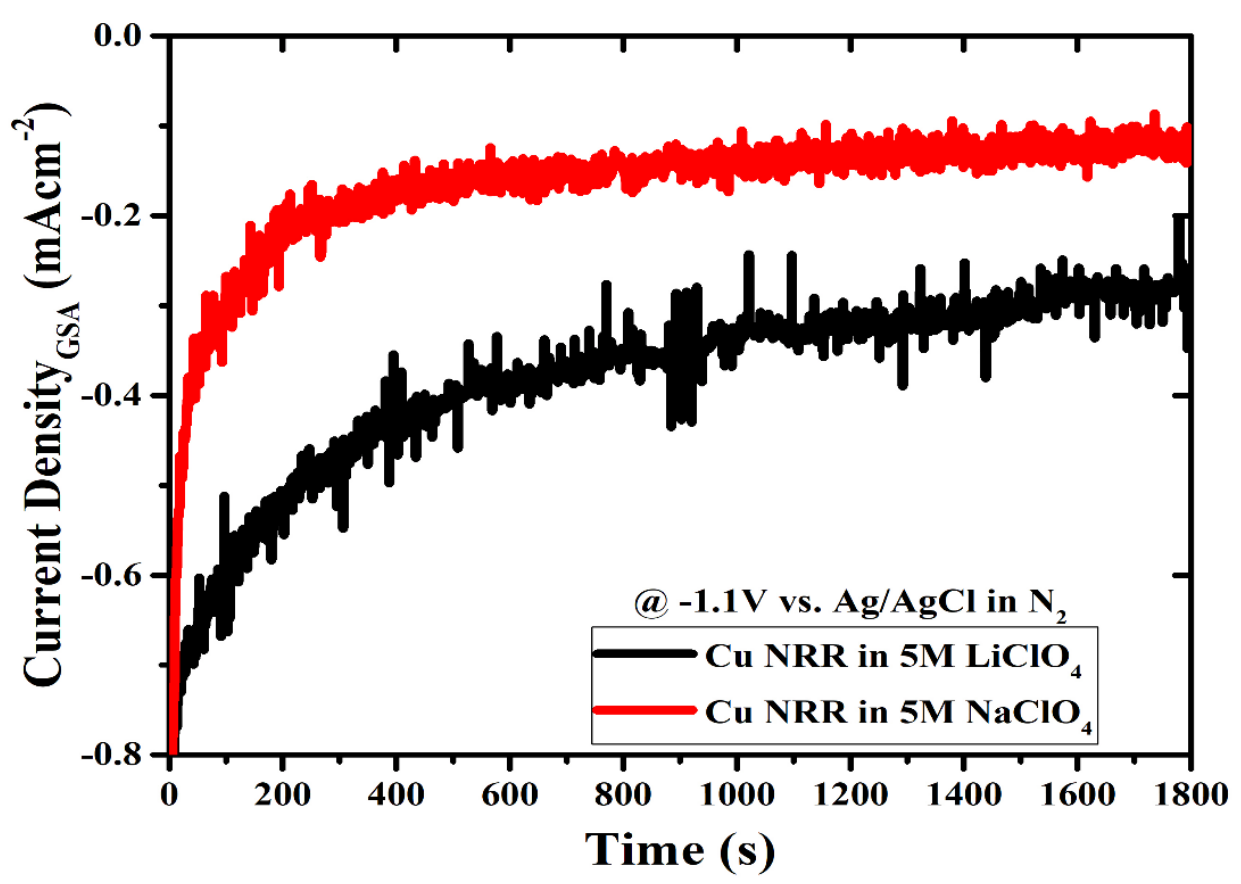

Figure S15: Chronoamperometry for $\mathrm{Cu}$ electrode at $-1.1 \mathrm{~V} v s . \mathrm{Ag} / \mathrm{AgCl}$ in $\mathrm{N}_{2}$ atmosphere in $5 \mathrm{M} \mathrm{NaClO}_{4}$ (red) and in $5 \mathrm{M} \mathrm{LiClO}_{4}$ (black). 


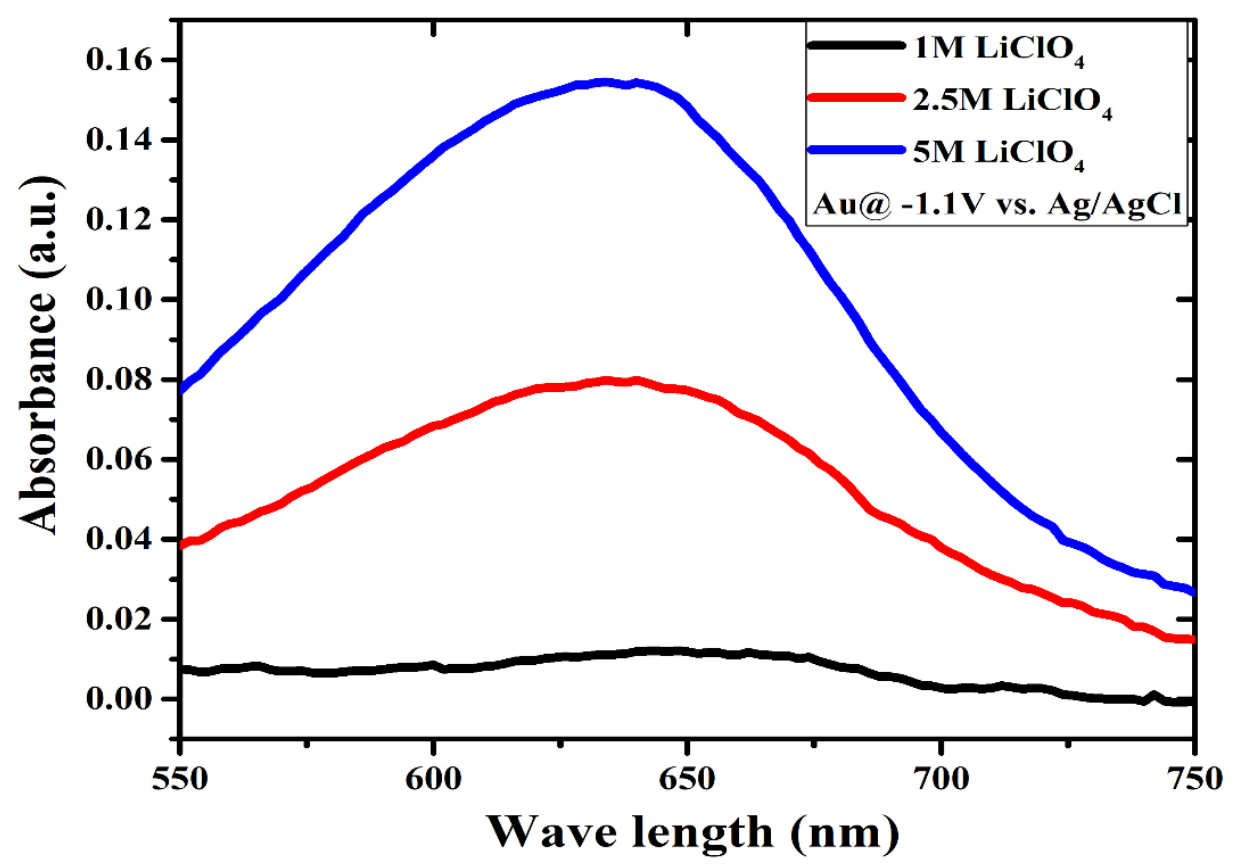

Figure S16:Absorbance vs. wavelengthfor $\mathrm{NH}_{3}$ for gold electrode $(\mathrm{Au})$ in different concentration of $\mathrm{LiClO}_{4}$ at $-1.1 \mathrm{~V} v$ s. $\mathrm{Ag} / \mathrm{AgCl}$.

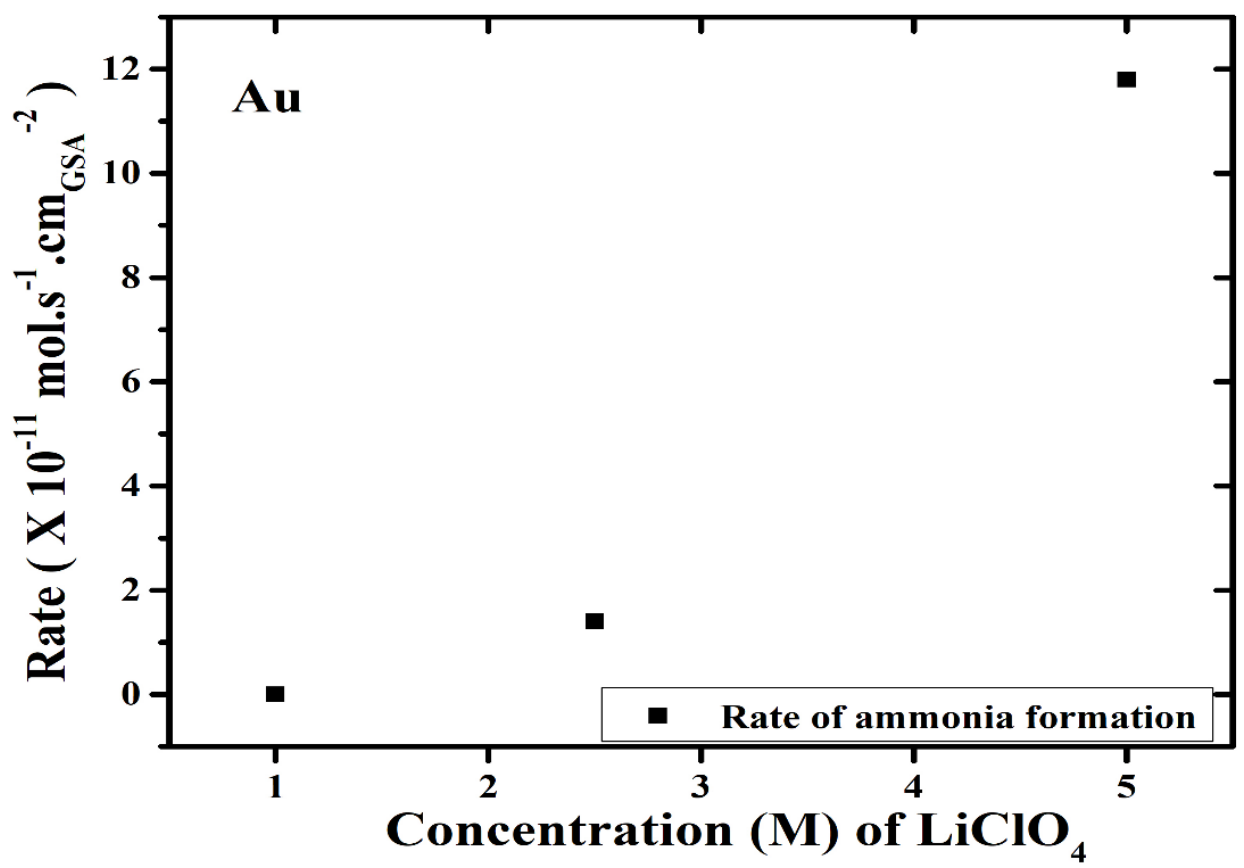

Figure S17: Rate of formation of ammonia at different potential vs. $\mathrm{Ag} / \mathrm{AgCl}$ on $\mathrm{Au}$ surface in $5 \mathrm{M} \mathrm{LiClO}_{4}$. 


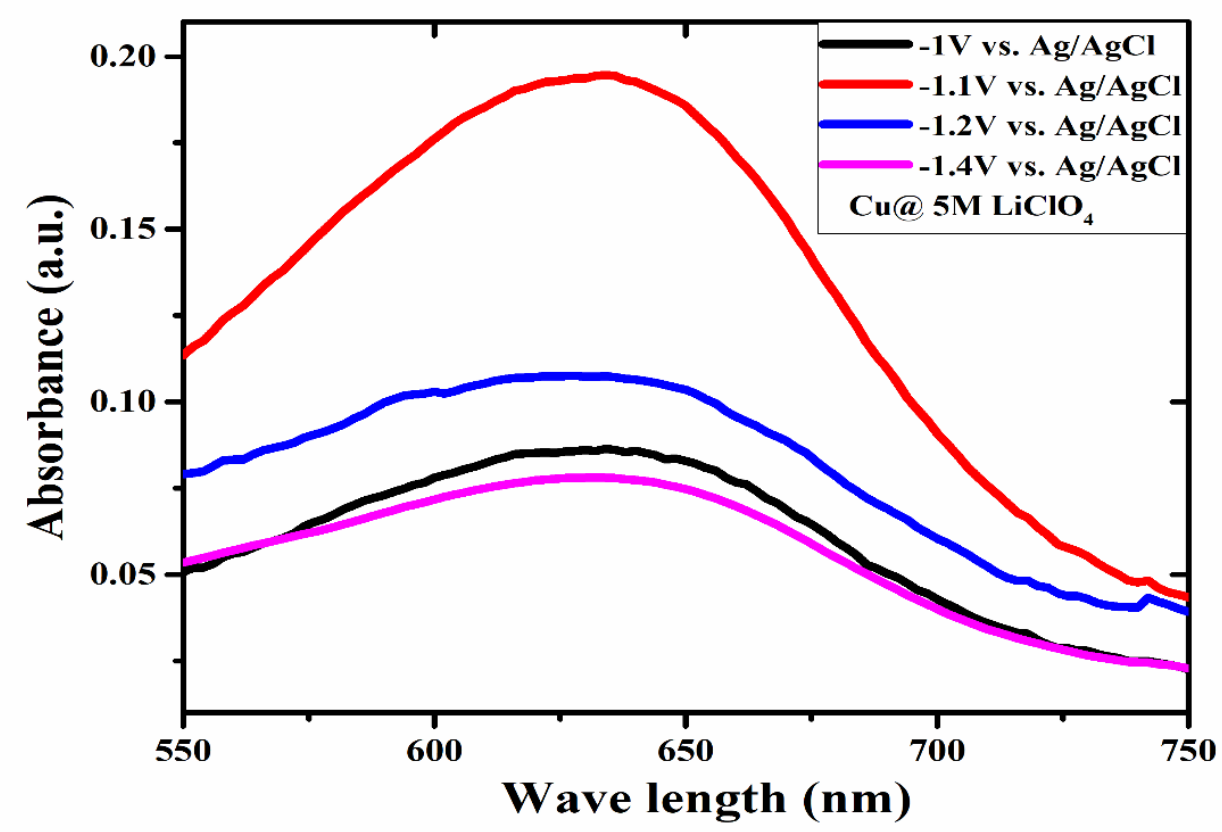

Figure S18: Absorbance vs. wavelength for $\mathrm{NH}_{3}$ for copper electrode $(\mathrm{Cu})$ in $5 \mathrm{M} \mathrm{LiClO}_{4}$ at different potential vs. Ag/AgCl.

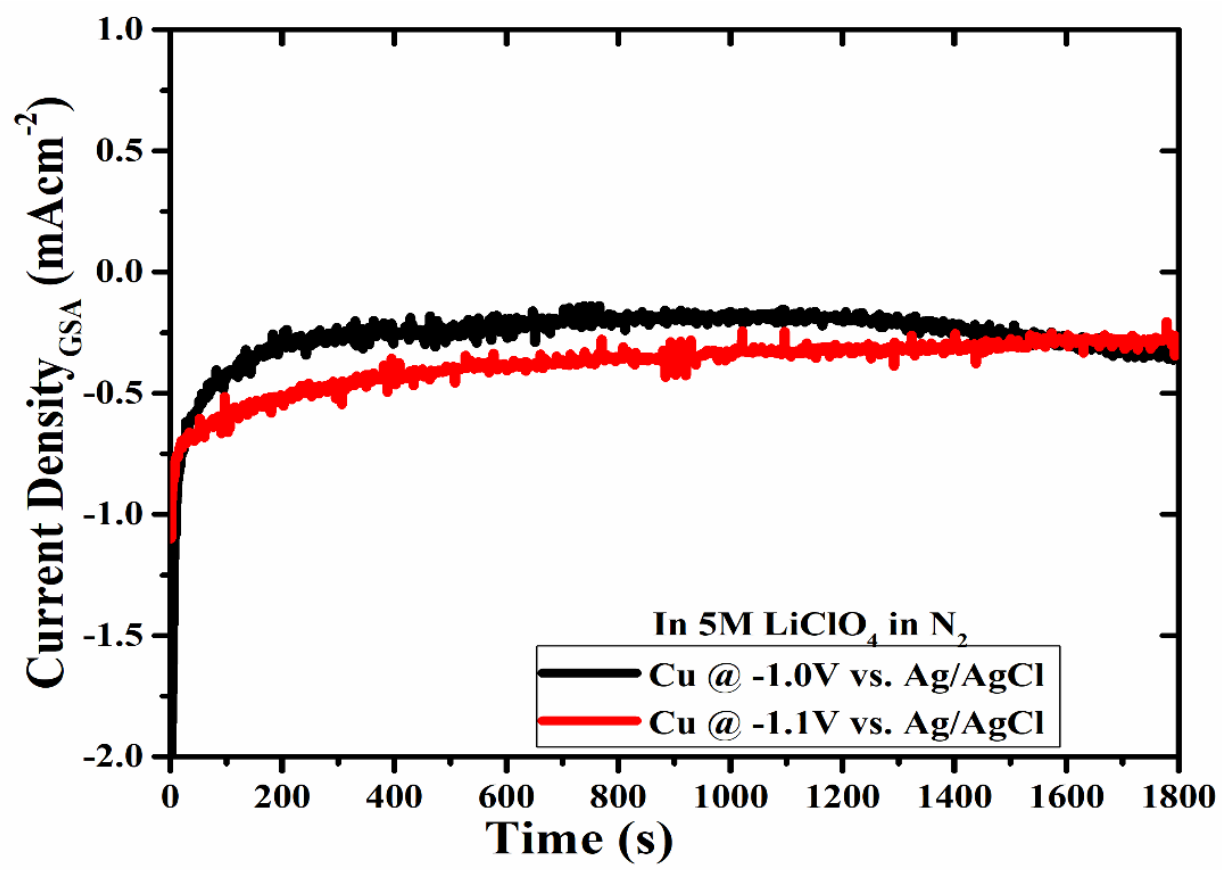

Figure S19: Chronoamperometries for $\mathrm{Cu}$ electrode in $\mathrm{N}_{2}$ atmosphere in $5 \mathrm{M} \mathrm{LiClO}_{4}$ at different potential vs. $\mathrm{Ag} / \mathrm{AgCl})$. 


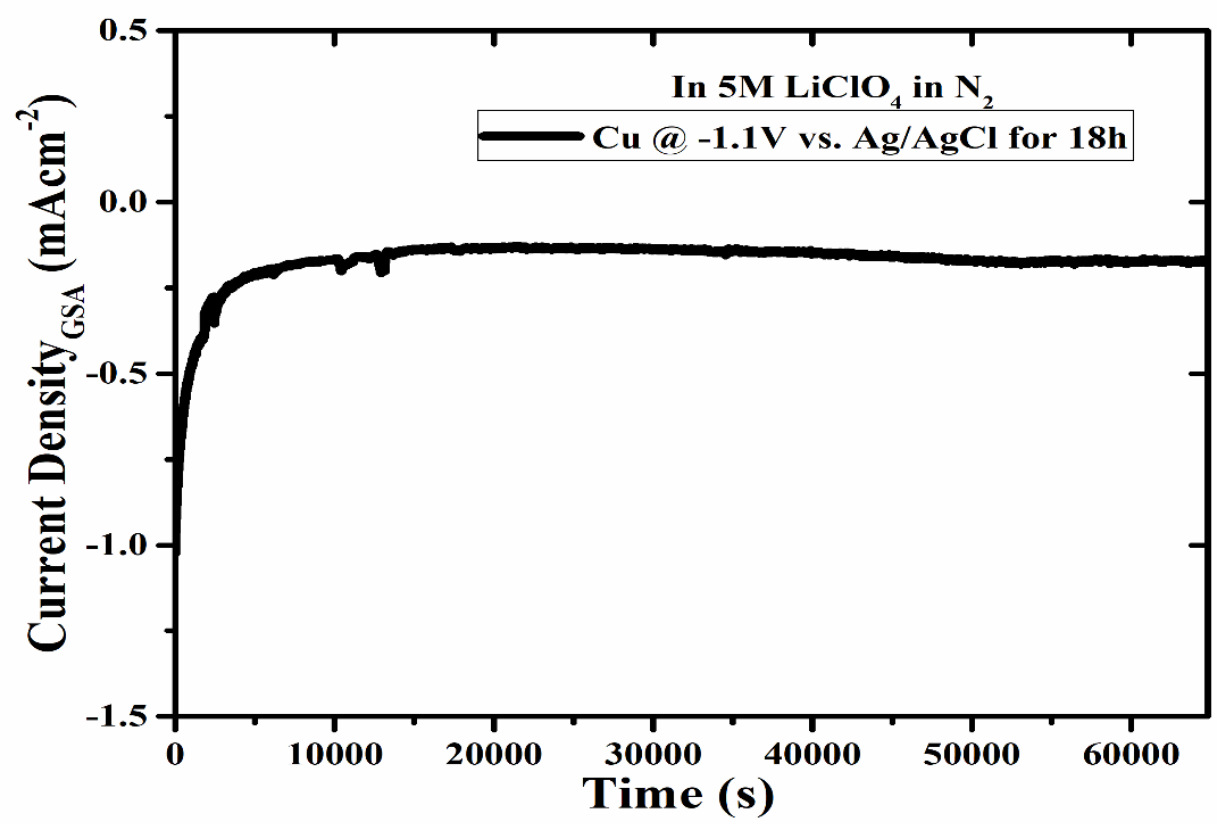

Figure S20:Stability of the electro-catalyst $(\mathrm{Cu})$ in $5 \mathrm{M} \mathrm{LiClO}_{4}$ for $\mathrm{N}_{2}$ reduction reaction for $18 \mathrm{~h}$.
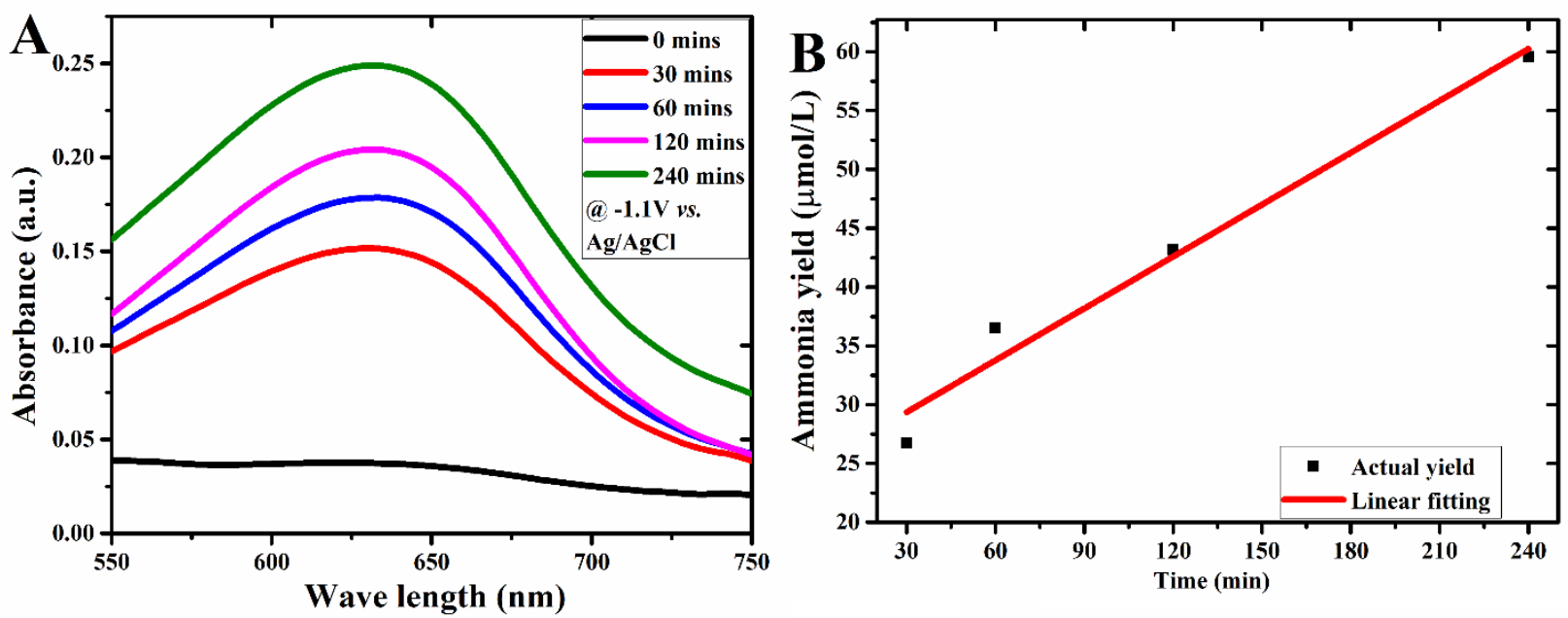

Figure S21:A) Absorbance vs. wavelength at different time for $\mathrm{Cu}$ in $5 \mathrm{M} \mathrm{LiClO} 4$ in $\mathrm{N}_{2}$ at $-1.1 \mathrm{~V}$ vs. $\mathrm{Ag} / \mathrm{AgCl}$ (geometric surface area $=1.7 \mathrm{~cm}^{2}$ and the rate of ammonia formation at 30 mins is $17.4 \times 10^{-11}$ mol. $\left.\mathrm{s}^{-1} \cdot \mathrm{cm}^{-2} \mathrm{GSA}, \mathrm{B}\right)$ Linearity of ammonia formation with respect to time. 

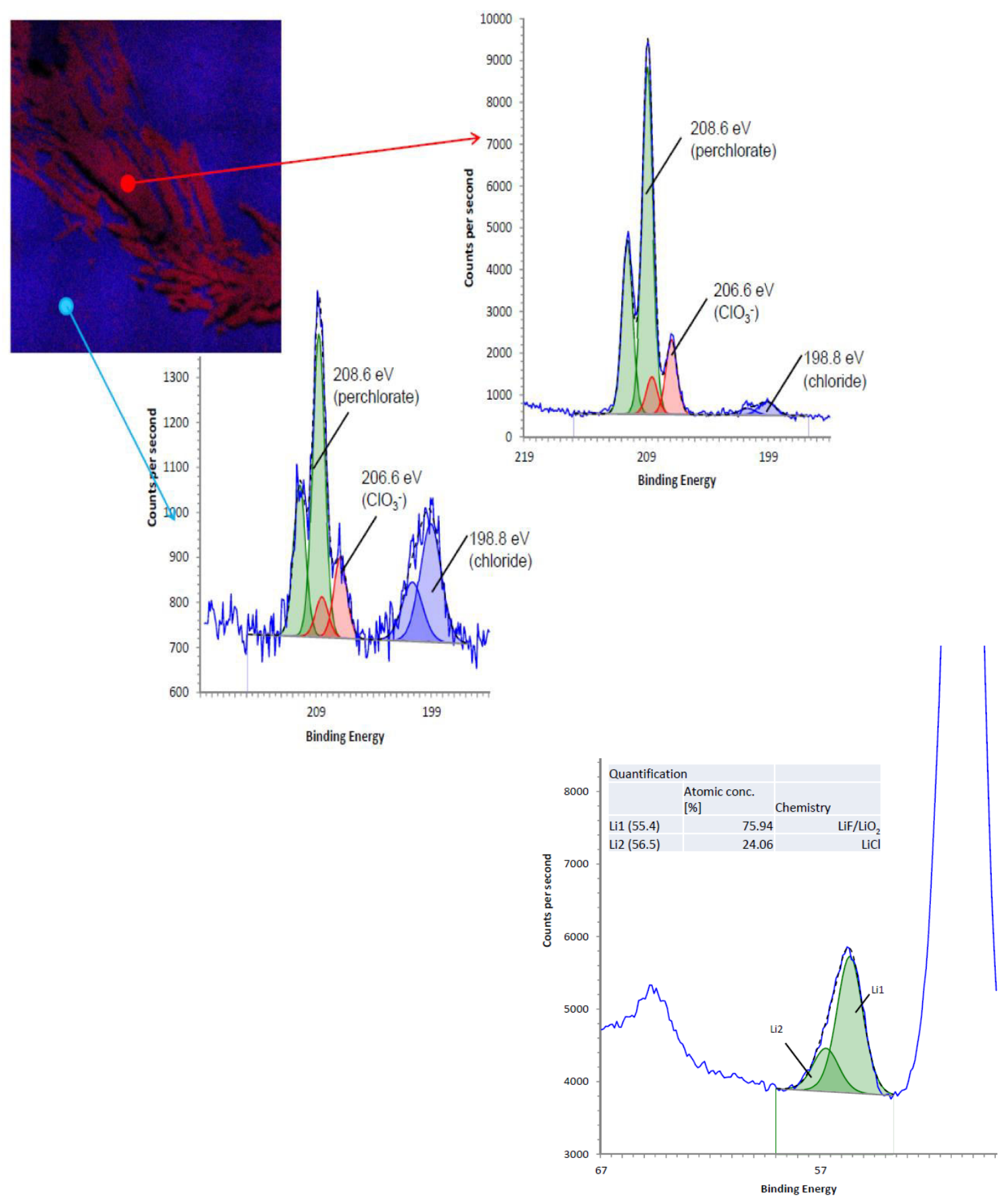

Figure S22: The photograph of the XPS analyses area ( $\mathrm{Cu}$ electrode) is shown in figure and the red part represents unwashed $\mathrm{LiClO}_{4}$ and the blue is $\mathrm{Cu}$ surface (where no visible $\mathrm{LiClO}_{4}$ deposition is present). Li spectrum is also shown in figure. 


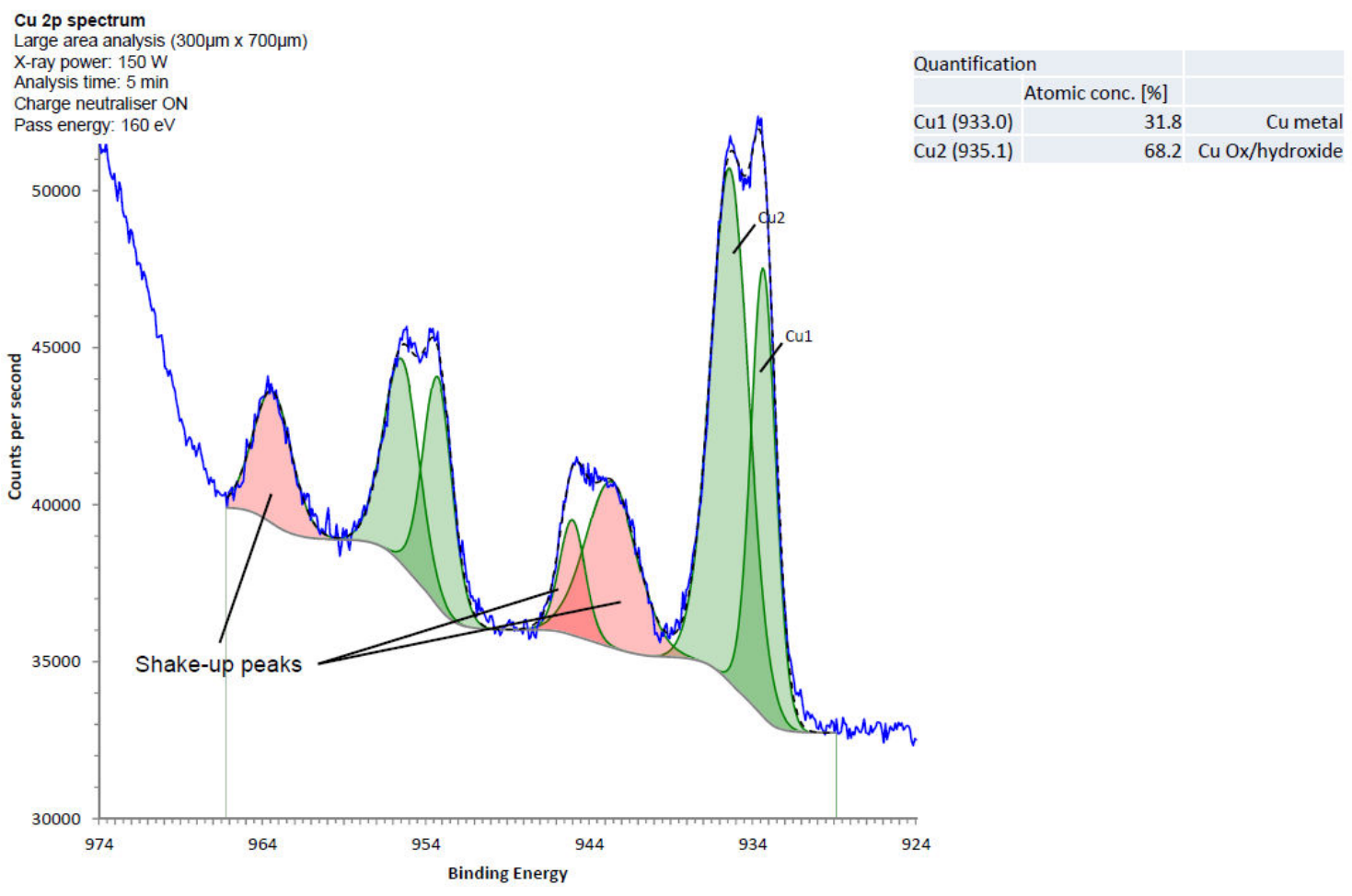

Figure S23: XPS spectrum of Cu electrode (from the surface without etching) after NRR. Partial oxidation of $\mathrm{Cu}$ is visible from the XPS analysis while depth profiling indicates the oxidation is happening mostly at the surface. 


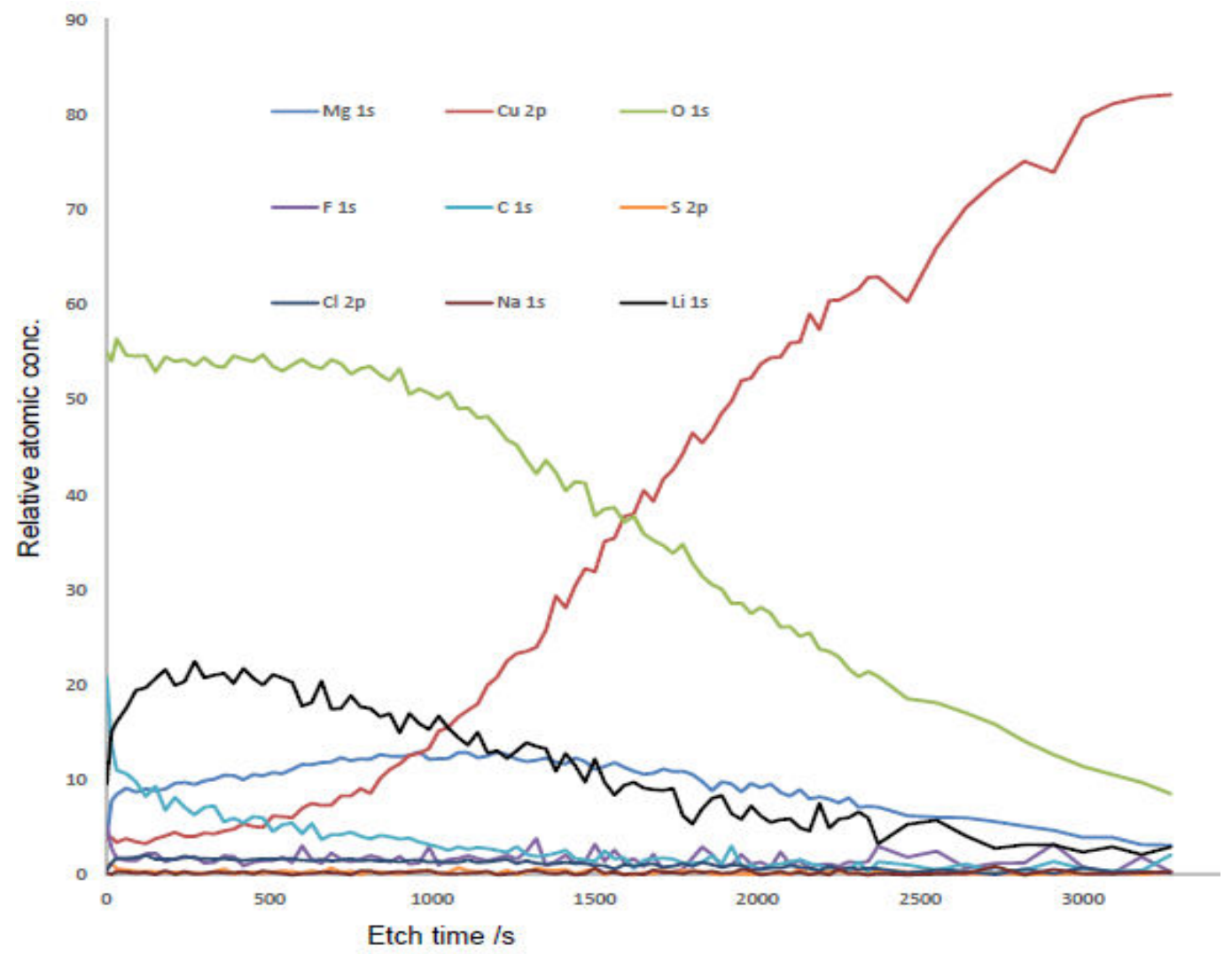

Figure S24:XPS depth profiling from $\mathrm{Cu}$ surface after NRR. The $\mathrm{Li}$ or $\mathrm{Cl}$ is only present at the surface of the electrode. The surface oxygen content might be due to the partial oxidation of $\mathrm{Cu}$. The other possible impurities of Li salt are also scanned, showing negligible presence.
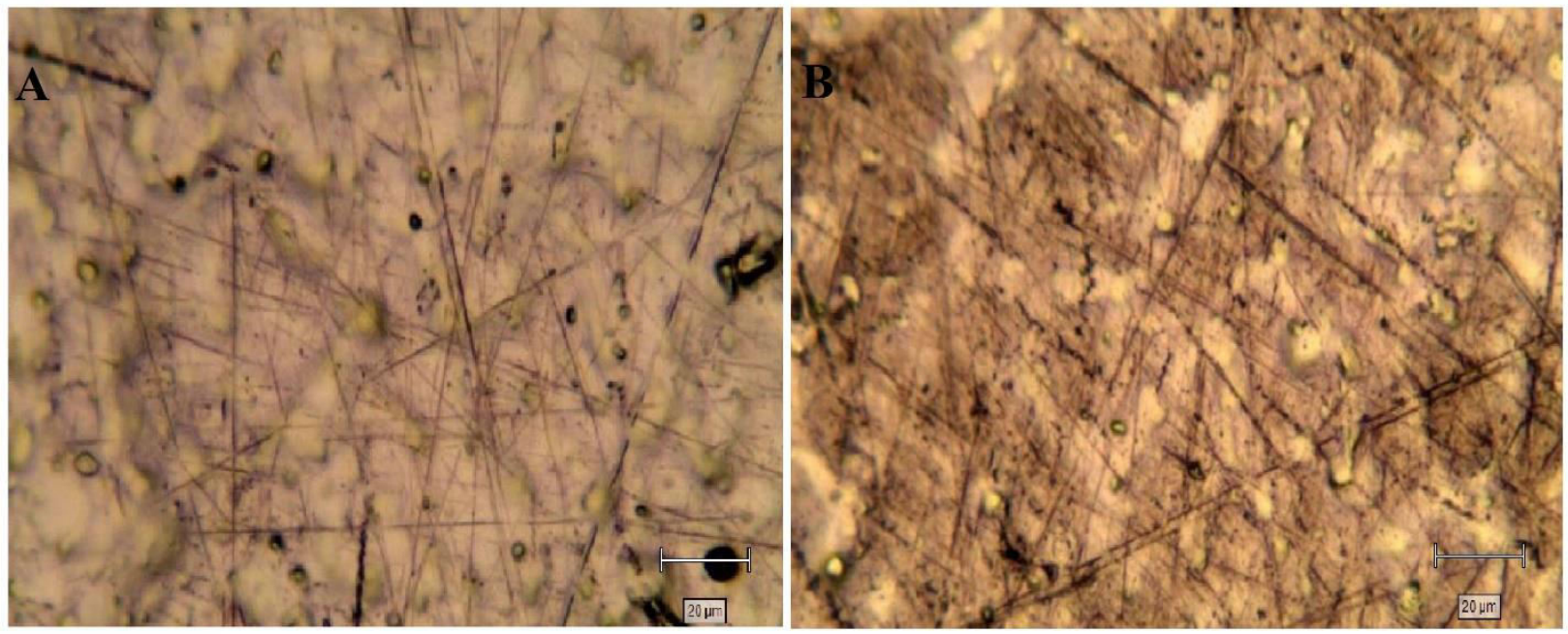

Figure S25:Cu electrode, A) before and B) after $\mathrm{NRR}$ in $5 \mathrm{M} \mathrm{LiClO}_{4}$ in $\mathrm{N}_{2}$ at $-1.1 \mathrm{~V} v s . \mathrm{Ag} / \mathrm{AgCl}$ for $30 \mathrm{~min}$. 


\begin{tabular}{|c|c|c|c|c|c|}
\hline Catalyst & Electrolyte & Condition & Yield & $\begin{array}{l}\text { Testing } \\
\text { Method }\end{array}$ & Ref \\
\hline $\mathrm{Ru} \mathrm{SAs/NC}$ & $0.05 \mathrm{M} \mathrm{H}_{2} \mathrm{SO}_{4}$ & $\begin{array}{l}\text { Ambient } \\
\text { condition }\end{array}$ & $\begin{array}{l}30.84 \mu \mathrm{gcm}^{-2} \mathrm{~h}^{-1} \\
29.6 \% \mathrm{FE}\end{array}$ & $\begin{array}{l}\text { Indophenol } \\
\text { blue } \\
\text { method }\end{array}$ & 10 \\
\hline $\begin{array}{l}\text { Nvacancies } \\
\text { engineered } \\
\text { polymeric carbon } \\
\text { nitride }\end{array}$ & $0.1 \mathrm{M} \mathrm{HCl}$ & $\begin{array}{l}\text { Room } \\
\text { temperature } \\
\text { and } \\
\text { atmospheric } \\
\text { pressure }\end{array}$ & $\begin{array}{l}8.09 \mu \mathrm{g} \cdot \mathrm{h}^{-1} \mathrm{mg}^{-1} \\
(\mathrm{NH} 3) 11.59 \% \mathrm{FE}\end{array}$ & $\begin{array}{l}\text { Indophenol } \\
\text { blue } \\
\text { method }\end{array}$ & 11 \\
\hline Carbon nano spikes & $\begin{array}{l}0.25 \mathrm{M} \text { aqueous } \\
\mathrm{LiClO}_{4}\end{array}$ & $\begin{array}{l}\text { Room } \\
\text { temperature } \\
\text { and } \\
\text { atmospheric } \\
\text { pressure }\end{array}$ & $\begin{array}{l}11.56 \% \mathrm{FE} \\
97.18 \mu \mathrm{g} \mathrm{h}^{-1} \mathrm{~cm}^{-2}\end{array}$ & $\begin{array}{l}\text { Indophenol } \\
\text { blue } \\
\text { method }\end{array}$ & 12 \\
\hline $\mathrm{Fe}$ & 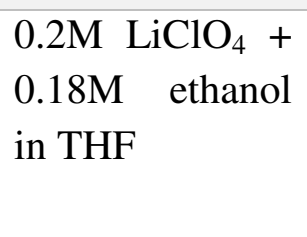 & $\begin{array}{l}\text { Room } \\
\text { temperature } \\
\text { and } 50 \text { atm } \\
\mathrm{N}_{2} \text { pressure }\end{array}$ & $57.7 \% \mathrm{FE}$ & $\begin{array}{l}\text { Indophenol } \\
\text { blue } \\
\text { method }\end{array}$ & 1 \\
\hline $\mathrm{Cu}$ & $5 \mathrm{M} \mathrm{LiClO}_{4}$ & $\begin{array}{l}\text { Room } \\
\text { temperature } \\
\text { and } \\
\text { pressure }\end{array}$ & $\begin{array}{l}12.1 \% \mathrm{FE} \text { and } \\
19.7 \times 10^{-11} \mathrm{~mol}^{-} \mathrm{s}^{-} \\
{ }^{1} . \mathrm{cm}_{\mathrm{GSA}}^{-2}\end{array}$ & $\begin{array}{l}\text { Indophenol } \\
\text { blue } \\
\text { method }\end{array}$ & $\begin{array}{l}\text { This } \\
\text { work }\end{array}$ \\
\hline
\end{tabular}

Table S1: Summary of literature reports on room temperature electrochemical $\mathrm{N}_{2}$ reduction reaction with different electrodes and electrolytes. 


\section{Reference:}

(1) Tsuneto, A.; Kudo, A.; Sakata, T. Lithium-Mediated Electrochemical Reduction of High Pressure N2 to NH3. J. Electroanal. Chem. 1994, 367 (1-2), 183-188.

(2) Bolleter, W. T.; Bushman, C. J.; Tidwell, P. W. Spectrophotometric Determination of Ammonia as Indophenol. Anal. Chem. 1961, 33 (4), 592-594.

(3) Watt, G. W.; Chrisp, J. D. A Spectrophotometric Method for the Determination of Hydrazine. Anal. Chem. 1952, 24 (12), 2006-2008.

(4) Greenlee, L. F.; Renner, J. N.; Foster, S. L. The Use of Controls for Consistent and Accurate Measurements of Electrocatalytic Ammonia Synthesis from Dinitrogen. ACS Catal. 2018, acscatal.8b02120.

(5) Bao, D.; Zhang, Q.; Meng, F.-L.; Zhong, H.-X.; Shi, M.-M.; Zhang, Y.; Yan, J.-M.; Jiang, Q.; Zhang, X.-B. Electrochemical Reduction of $\mathrm{N}_{2}$ under Ambient Conditions for Artificial $\mathrm{N}_{2}$ Fixation and Renewable Energy Storage Using $\mathrm{N}_{2} / \mathrm{NH}_{3}$ Cycle. Adv. Mater. 2017, 29 (3), 1604799.

(6) Yang, X.; Nash, J.; Anibal, J.; Dunwell, M.; Kattel, S.; Stavitski, E.; Attenkofer, K.; Chen, J. G.; Yan, Y.; Xu, B. Mechanistic Insights into Electrochemical Nitrogen Reduction Reaction on Vanadium Nitride Nanoparticles. J. Am. Chem. Soc. 2018, 140, 1338713391.

(7) Soler, M.; Artacho, E.; Gale, J. D.; Garc, A.; Junquera, J.; Ordej, P.; Daniel, S. The Siesta Method for Ab Initio Order- N Materials Simulation. J. Phys. Condens. matter 2002, 14 (11), 2745.

(8) Hammer, Bjørk; Hansen, Lars Bruno; Nørskov, J. K. Improved Adsorption Energetics within Density-Functional Theory Using Revised Perdew-Burke-Ernzerhof Functionals. Phys. Rev. B 1999, 59 (11), 7413-7421.

(9) Paxton, M. M. and A. T. High-Precision Sampling for Brillouin-Zone Integration in Metals. Phys. Rev. B 1989, 40 (6), 3616-3621.

(10) Geng, Z.; Liu, Y.; Kong, X.; Li, P.; Li, K.; Liu, Z.; Du, J. Achieving a Record-High Yield

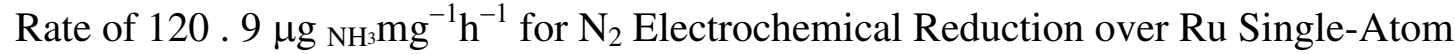
Catalysts. Adv. Mater. 2018, 1803498, 2-7.

(11) Lv, C.; Qian, Y.; Yan, C.; Ding, Y.; Liu, Y.; Chen, G.; Yu, G. Defect Engineering MetalFree Polymeric Carbon Nitride Electrocatalyst for Effective Nitrogen Fixation under Ambient Conditions. Angew. Chemie - Int. Ed. 2018, 57, 10246-10250.

(12) Song, Y.; Johnson, D.; Peng, R.; Hensley, D. K.; Bonnesen, P. V.; Liang, L.; Huang, J.; Yang, F.; Zhang, F.; Qiao, R.; et al. A Physical Catalyst for the Electrolysis of Nitrogen to Ammonia. Sci. Adv. 2018, 4 (4), 1-9. 
